\title{
Markovian Social Security in Unequal Societies*
}

\author{
Kaiji Chen ${ }^{\dagger}$ \\ University of Oslo \\ Zheng Song $\ddagger$ \\ Fudan University
}

This version: January, 2009

\begin{abstract}
In this paper, we develop a dynamic politico-economic theory of social security to address two questions. First, how is social security sustained? Second, how does inequality affect the size of social security, and can the theoretical predictions be consistent with the observed puzzling relationships between inequality and the size of social security? As a stark framework, our model economy features the absence of altruism, commitment, reputation mechanism and electoral uncertainty. We characterize analytically a Markov perfect equilibrium and find that the joint between Markovian tax policy and tax distortion on private investment shapes an intertemporal policy rule linking taxes positively over time. The positive intertemporal tax linkage, by allowing current taxpayers to influence their own future social security benefit, provides the political support for social security. Moreover, we find that a larger wage inequality weakens the intertemporal tax linkage and, thus, reduces inter-generational redistributive benefit. This may lead to a smaller size of social security. Our theoretical predictions are in line with both time-series and cross-country correlations between inequality and social security.
\end{abstract}

JEL Classification: E60 H55 P16

Keywords: Intertemporal Tax Linkage, Markov Perfect Equilibrium, Political Economy, Redistribution, Social Security, Wage Inequality.

${ }^{*}$ We thank John Hassler, Dirk Niepelt, Torsten Persson, Kjetil Storesletten and Fabrizio Zilibotti for helpful discussions.

${ }^{\dagger}$ Department of Economics, University of Oslo, Box 1095, Blindern, 0371 Oslo, Norway. Phone: (+47) 22855495. Email: kaijic@econ.uio.no

${ }^{\ddagger}$ School of Economics, Fudan University, Shanghai 200433, China. Phone: (+86) 2165643514. Email: zsong@fudan.edu.cn 


\section{Introduction}

For most OECD countries, unfunded social security programs redistribute resources both across generations (from workers to retirees) and within generations (from the rich to the poor). ${ }^{1}$ Since inter- and intra-generational redistributive elements are intertwined through a single policy instrument, the political choice on social security necessarily involves an interaction of redistributive considerations along both dimensions. Exploring this interaction would not only provide new insight on the politico-economic mechanism of social security, but also be interesting in light of two puzzling observations regarding inequality and welfare states. First, many cross-country empirical studies found virtually no, or even a negative relationship, between inequality and the size of welfare states. ${ }^{2}$ Second, for many industrial democracies, wage inequality featured an upward shift during the 1980s and 1990s, while the growth of social security slowed down or even stopped. The archetypal case is the U.S.: The size of social security benefit was cut back in the 1980 s, whereas wage inequality increased sharply. ${ }^{3}$

This paper, therefore, poses a twofold question: First, how is the social security system sustained? More precisely, given the temporal separation of contribution and benefit, why do a majority of (self-interested) working generations contribute to the system, which redistributes to a minority of the old at any point in time? Second, how does inequality affect the size of social security, and can political decisions be reconciled with the observed puzzling correlation between inequality and the size of social security, both across countries and across time periods? While some theories have been proposed to address the first question, most of them have either been silent on the second or have delivered predictions opposite to the above empirical observations. In this paper, we take an answer to the second question as a natural check of the empirical relevance of our proposed theory.

To provide a stark framework for analyzing the sustainability of social security, we consider a dynamic political economy featuring the absence of altruism, commitment, reputation mechanism and electoral uncertainty (e.g., probabilistic voting). ${ }^{4}$ In our model, self-interested forward-looking citizens vote repeatedly for a social security tax. Moreover, we focus exclusively on Markov perfect equilibria with the median voter being taxpayers.

\footnotetext{
${ }^{1}$ For example, the original Social Security Act of 1935 in the U.S. embodied two principles that still guide benefit payment today: Benefit depends on the history of work in covered employment, and replaces a higher proportion of earnings for low earners.

${ }^{2}$ See, for example, Perotti (1996), Lindert (1996) and Rodriguez (1998).

${ }^{3}$ See Section 5 for a detailed discussion of the evidence.

${ }^{4}$ These approaches have been widely adopted in the literature on the sustainability of social security.
} 
Our model generates two key results. First, the impact of a current tax on future decisive voters' redistributive benefit shapes an intertemporal tax linkage that implies positively correlated social security tax rates across time. The positive intertemporal tax linkage, by allowing the current median voter (taxpayers) to influence their own future social security benefit, provides them the incentive to support social security. Second, we find that a larger wage inequality weakens the intertemporal tax linkage and, thus, reduces inter-generational redistributive benefit. This may lead to a smaller size of social security. As a result, our theoretical predictions regarding the correlation between wage inequality and the size of social security are in line with the above two empirical observations.

Our workhorse is a three-period overlapping-generation model. Individuals work in the first two periods of their lives and retire when old. They can invest in human capital at birth to increase productivity and, thus, wage income during both working periods - youth and middle-age. All individuals have linear utility on consumption, and human-capital investment involves a quadratic loss for the young. To incorporate intra-generational redistribution of social security, we introduce ex-ante within-cohort heterogeneity by assuming that each individual is born with either high or low ability and, therefore, receives either a high or a low wage rate for each unit of human capital. Taxes are imposed on wage income of the young and the middle-aged to finance social security benefit for the old. Each period, social security benefit is uniformly distributed across different types of old agents, reflecting the intra-generational redistributive feature of social security in unequal societies.

We solve for differentiable Markov perfect equilibria in which the policy rule is a differentiable function of payoff-relevant state variables. In the class of equilibria we consider, the middle-aged agents with a low wage, referred to as "the middle poor" henceforth, are always the median voter and decisive for the political choice on the social security tax. Accordingly, the payoff-relevant state variable is the human-capital stock of the middle poor. As in standard theories, the human-capital stock of the middle poor negatively affects their future social security benefit, from both inter- and intra-generational redistribution, and, therefore, their tax choice. This establishes a Markovian policy rule, which links social security tax negatively to the human capital stock. Such a Markovian tax rule implies a standard effect of wage inequality: A larger wage inequality leads to a higher tax since it relatively lowers humancapital investment and, thus, the human-capital stock of the poor. We refer to this effect as the "redistributive effect."

More importantly, the Markovian tax rule allows the current median voter to indirectly 
influence future political decisions. ${ }^{5}$ Consider an increase in today's social security tax rate, which discourages the human-capital investment of the young. The Markovian tax rule implies a higher tax rate tomorrow due to more redistributive benefit for tomorrow's decisive voters (the current young). In other words, the joint between the Markovian tax rule and private investment decisions creates a positive intertemporal tax linkage. Rationally perceiving this linkage, the current median voter understands that the more taxes she pays today, the more social security benefit she will receive tomorrow. As a result, she may vote for a positive tax to trade off her current tax burden against her future redistributive benefit.

The intertemporal tax linkage reveals a novel channel through which intra-generational inequality affects inter-generational redistributive benefit and, thus, the size of social security. In a society with larger wage inequality, the relatively lower wage rate for the poor dampens the impact of the current tax on human-capital investment of the young poor - the median voter in the next period. Consequently, the future tax becomes less responsive to the current one. The weakened intertemporal tax linkage implies less inter-generational redistributive benefit for the current median voter. Anticipating this, she will choose a lower tax. We label this effect of wage inequality the "strategic effect."

The presence of the strategic effect generates surprising theoretical predictions. First, we find that a permanent positive shock to wage inequality leads to a contemporaneous cutback in social security. This is because upon impact, the human-capital stock of the middle poor is predetermined. As a result, the redistributive effect is shut down and only the strategic effect plays a role.

We then investigate the long-run relationship between wage inequality and social security. In particular, we find that the steady-state tax rate is an inverted U-shaped function of wage inequality. A more unequal society may actually have a smaller steady-state size of social security if wage inequality is sufficiently large. Since both human capital and tax policies are endogenously determined in the long run, the long-run impact of wage inequality embodies both strategic and redistributive effects. The negative correlation between inequality and social security originates from the dominant role of the strategic effect with large inequality. Only after inequality falls below some critical level does the redistributive effect start to overshadow the strategic effect, rendering the correlation positive, as the standard theory implies.

The above predictions regarding both short-run and long-run effects of wage inequality on social security are in line with empirical facts. For time-series evidence, we look at the U.S. case,

\footnotetext{
${ }^{5}$ Due to the lack of commitment in our model, the current constituency has no way to directly affect future legislation.
} 
for which a long span of high-quality data exists. Applying cointegration techniques, we find a negative long-run correlation between wage inequality and the size of social security benefit in the U.S. Moreover, vector error-correction models confirm that a rise in wage inequality reduces social security benefit substantially in the short run. For example, our estimates indicate that the increase in wage inequality from the late 1970s to the mid-1980s can explain a large proportion of the observed decline in the size of social security benefit from 1982 to the late 1980s. As a further check for the model's long-run implications, we use data on 19 OECD countries and, for each country, compute the average earnings inequality and social security size between 1980 and 2000. We find that countries with smaller earnings inequality have, on average, larger social security expenditures as a percentage of GDP.

Our paper contributes to the literature on the political sustainability of social security in several aspects. One of the key issues is the temporal separation of contribution and benefit. The literature so far takes two approaches to address the issue. The first circumvents the temporal separation problem by assuming that the welfare of benefit recipients weighs somehow in the preference of policy makers. ${ }^{6}$ The second approach attempts to construct equilibria in which self-interested taxpayers support the system. However, the literature often resorts to ad hoc intertemporal policy rules. ${ }^{7}$ In our model, the intertemporal tax linkage arises endogenously from the interaction between private decisions and political choices. Aside from theoretical appeal, the endogenous intertemporal tax linkage has also empirical relevance: The associated strategic effect may cause a negative correlation between wage inequality and social security. By contrast, ad hoc intertemporal tax linkage assumes away the strategic effect and, therefore, always predicts a positive correlation.

Another issue in the political sustainability of social security is the indeterminacy of political equilibria. In previous efforts to rationalize ad hoc intertemporal policy rules, future policy choices are often conditioned to variables that are payoff-irrelevant for future policy makers. This problem exists not only in trigger strategy equilibria, but also in some recent studies seeking to adopt the Markov strategy approach (see Azariadis and Galasso, 2002 and Forni, 2005). In our model, individuals today anticipate future policies according to future politico-

\footnotetext{
${ }^{6}$ Examples of this sort include altruism, probabilistic voting (Gonzalez-Eires and Niepelt, 2008, Song, 2008) or gerontocracy (Mulligan and Sala-i-Martin, 1999).

${ }^{7}$ Specifically, previous work along this vein typically assumes that the future tax is related to the current tax in an ad hoc way. For example, in "once-and-for-all-voting," the initial median voter expects future generations to commit fully to his choice of the tax for at least his lifetime (See, among others, Browning, 1975 and Conesa and Krueger, 1999). In the "trigger strategy," though expectation of future policy choice is based on a system of rewards and punishments in an infinite dynamic game, the choice of future generations is confined to either approving or rejecting the tax rate chosen in the initial period (See, among others, Cooley and Soares, 1999 and Boldrin and Rustichini, 1999).
} 
economic fundamentals that are indeed payoff-relevant for future median voters. Self-fulfilling expectations are, therefore, excluded. This, in turn, pins down the current policy as a function of the current payoff-relevant state variable. Such a Markovian policy rule eliminates the indeterminacy of political equilibria and can provide testable empirical predictions. ${ }^{8}$

This paper also contributes to the discussion on inequality and welfare states. Empirical studies (e.g., Lindert, 1996 and Rodriguez, 1998) have found a negative correlation between income inequality and the size of welfare states across the OECD. ${ }^{9}$ Our paper provides additional support for this negative correlation from the perspective of social security, the largest part of government transfers. Moreover, our time-series evidence contributes to the literature by showing both a short-run and a long-run negative correlation between wage inequality and social security in the U.S. On theoretical grounds, the literature attempts to explain the negative correlation by focusing on roles other than redistribution-say, social insurance under incomplete markets (e.g., Benabou, 2000 and Moene and Wallerstein, 2001). As a complement to the literature, our theory shows that in the context of social security, the negative correlation can well be explained by the strategic effect through which intra-generational inequality may affect inter-generational redistributive benefit. ${ }^{10}$

Our work is part of a growing literature on dynamic politico-economic equilibrium, in which current voting may change future politico-economic fundamentals and, hence, affect future policy outcomes. ${ }^{11}$ The methodology used in this paper is closely related to Hassler, Rodriguez Mora, Storesletten and Zilibotti (2003, henceforth HRSZ). HRSZ analyze the dynamics of the welfare state in Markov perfect equilibria allowing closed-form solutions. In their paper, the current median voter can vote strategically to influence the identity of the median voter in the following period. This gives rise to an intertemporal policy linkage similar to that in our model. We share with HRSZ in the methodology to build up the intertemporal policy

\footnotetext{
${ }^{8}$ Previous studies suggest that the fundamental linkage between policy choices and payoff-relevant state variables may help to overcome the indeterminacy of equilibria. For example, McCallum (1983) finds that in a wide class of linear rational expectation models, non-uniqueness of solutions occurs because unnecessary or 'extraneous' components are permitted to influence expected (and, therefore, actual) values of endogenous variables. Maskin and Tirole (2001) argue that Markov perfect equilibrium, by preventing non-payoff-relevant variables from affecting strategic behavior, is often successful in eliminating or reducing a large multiplicity of equilibria in dynamic games.

${ }^{9}$ One exception is Tabellini (2000), which, by applying cross-country regression for more than 40 countries, finds that the size of social security systems is positively correlated with income inequality. Persson and Tabellini (2000, Chapter 6), however, note that the measure of inequality is bound to be imperfect for such a large sample of countries.

${ }^{10}$ Note that if the old and the rich workers form a coalition, it might be possible to generate a negative correlation between inequality and the size of social security. However, this implies either a regressive tax or a convex benefit function of contribution, which is counterfactual.

${ }^{11}$ See, among others, Krusell and Rios-Rull (1999), Azzimonti Renzo (2005), Song (2007) and Song, Storesletten and Zilibotti (2007).
} 
rule and characterize analytically Markov perfect equilibrium. However, their model economy does not feature a temporal separation of redistributive contribution and benefit because, by construction, the decisive voter must be the transfer recipient (the old). Therefore, unlike our model, theirs exhibits no strategic effects. The correlation between wage inequality and the size of welfare states simply depends on whether the old poor or the old rich are decisive.

The paper is organized as follows. Section 2 describes the economic environment and the Ramsey solution regarding policy choices. The political equilibrium is characterized in Section 3. Section 4 examines the impact of wage inequality on social security. Section 5 discusses the empirical evidence on the relationship between inequality and social security. Section 6 concludes.

\section{The Model Economy}

Consider a small open economy inhabited by an infinite sequence of overlapping generations. Each generation lives three periods. An individual works in the first two periods of her life and retires in the last. Labor supply in each of the first two periods is inelastic and normalized to unity. The young can make human-capital investment to increase labor productivity.

There is heterogeneity within each cohort. Individuals are born with either high or low ability. High- (low-) ability individuals receive a high (low) wage rate per unit of human capital, denoted as $w^{s}\left(w^{u}\right)$. For notational convenience, agents with high (low) ability will be referred to as the rich (the poor). Let $h_{t}^{j}$ be the human-capital investment of a young individual born at time $t$ with type $j, j=s, u$. Human capital and wage income at both working ages equal $h_{t}^{j}$ and $w^{j} h_{t}^{j}$, respectively. ${ }^{12}$

We consider a pay-as-you-go social security system. The flat-rate payroll tax rate $\tau_{t}$ is determined through a political process that will be specified below. $\tau_{t}$ is imposed on working generations to finance social security benefit. In reality, social security systems contain both actuarial and redistributive components. For analytical convenience, in this dynamic model we take the degree of actuarial fairness as exogenously given, rather than as a political choice. This assumption also captures the idea that, in reality, the degree of actuarial fairness of a social security system is more stable over time than the contribution rate, which may well adjust annually. ${ }^{13}$ In addition to inter-generational transfers, our pay-as-you-go social security system also bears intra-generational redistributive elements. More specifically, following Conesa and

\footnotetext{
${ }^{12}$ We could assume that human capital depreciates over time. Then, wage incomes for the middle-aged would be equal to $\delta w^{j} h_{t}^{j}$, where $1-\delta$ is the depreciation rate. The main results would not change under this extension.

${ }^{13}$ See Conde-Ruiz and Profeta (2007) for a static model with political choices on both the contribution rate and the degree of actuarial fairness.
} 
Krueger (1999) and many others, we assume that social security benefit is evenly distributed among old individuals (i.e. "non-actuarially fair"). ${ }^{14}$

Then, the lifetime wealth $A_{t}^{j}$ follows

$$
A_{t}^{j}=\left(1-\tau_{t}\right) w^{j} h_{t}^{j}+\frac{\left(1-\tau_{t+1}\right) w^{j} h_{t}^{j}}{R}+\frac{p_{t+2}}{R^{2}},
$$

where $p_{t+2}$ stands for social security benefit per retiree born at time $t$.

To obtain closed-form solutions, we assume agents to have a linear-quadratic preference over lifetime wealth and costs of human-capital investment:

$$
\max _{h_{t}^{j}} A_{t}^{j}-\frac{1}{2}\left(h_{t}^{j}\right)^{2}
$$

subject to (1). Solving (2) yields

$$
h_{t}^{j}=\left(1-\tau_{t}+\frac{1-\tau_{t+1}}{R}\right) w^{j} .
$$

For each type $j$, human-capital investment increases in wage rate and decreases in tax rates. (2) deserves comment. By assuming the linear preference, we actually shut down private saving and therefore the interaction between savings and social security. However, as will be shown below, the human-capital investment in our model plays essentially the same role as savings in the determination of social security; less human-capital investment (or savings) today leads to more social security benefit tomorrow. An extension of the present model by incorporating the intertemporal choice on consumption, therefore, will only complicate the analysis and add no major new insight. ${ }^{15}$

The proportion of the poor is a constant $\lambda$ in each cohort. We assume $\lambda \geq 1 / 2$ so that the poor are the majority of the population. The weighted average wage incomes for the cohort born at time $t$, denoted by $\bar{w}^{t}$, are equal to

$$
\bar{w}_{t}^{t}=\bar{w}_{t+1}^{t}=\lambda w^{u} h_{t}^{u}+(1-\lambda) w^{s} h_{t}^{s} .
$$

The first equality is due to the fact that the middle-aged have the same productivity as when they are young.

Assume that the gross population growth rate is a constant $n>1$. Plugging (3) into (4), we obtain the output per retiree, which will be useful in the analysis below:

$$
\begin{aligned}
y_{t} & =n \bar{w}_{t}^{t-1}+n^{2} \bar{w}_{t}^{t} \\
& =n\left(\frac{h_{t-1}^{u}}{w^{u}}+n\left(1-\tau_{t}+\frac{1-\tau_{t+1}}{R}\right)\right) .
\end{aligned}
$$

\footnotetext{
${ }^{14}$ Our results on both the political sustainability and the size of social security do not change qualitatively if we assume a more actuarially fair system.

${ }^{15}$ In an earlier version of this paper, we show that the mechanism emphasized here also applies in a model with private savings, which gives qualitatively the same results as below.
} 
Here, we normalize $\lambda\left(w^{u}\right)^{2}+(1-\lambda)\left(w^{s}\right)^{2}$ to unity so that wage inequality has no first-order effect on the tax base. ${ }^{16}$ We also use the fact that $h_{t-1}^{s} / h_{t-1}^{u}=w^{s} / w^{u}$, implied by (3). The output per retiree $y_{t}$ is the current tax base for social security benefit. It is also convenient to have the future tax base $y_{t+1}$, which is determined by $h_{t}^{j}$ and $h_{t+1}^{j}$ and, hence, $\tau_{t}, \tau_{t+1}$ and $\tau_{t+2}$.

$$
y_{t+1}=\Pi-n\left(\tau_{t}+\left(n+\frac{1}{R}\right) \tau_{t+1}+\frac{n}{R} \tau_{t+2}\right),
$$

where $\Pi \equiv n(1+n)\left(1+\frac{1}{R}\right)$. Note that $y_{t+1}$ is independent of the current human-capital stock $h_{t-1}^{j}$.

We assume that the budget of the social security system must balance in each period. This implies that in each period, total benefit paid to the old equal total contribution collected from working generations:

$$
p_{t}=\tau_{t} y_{t}
$$

The size of the social security system, as measured by the share of total social security benefit in total output, $p_{t} / y_{t}$, is equal to $\tau_{t}$ in this simple model. Hence, the flip sides of the sustainability and the size of social security are the sustainability of a positive $\tau_{t}$ and its level.

Substituting (6) and (7) into (1), the indirect utility functions of the middle-aged and old of type $j$, denoted by $v^{m, j}$ and $v^{o, j}$, can be written as

$$
\begin{aligned}
v^{m, j}\left(h_{t-1}^{j}, \tau_{t}, \tau_{t+1}, \tau_{t+2}\right) & =\left(1-\tau_{t}\right) w^{j} h_{t-1}^{j}+\frac{\tau_{t+1}\left(\Pi-n\left(\tau_{t}+\left(n+\frac{1}{R}\right) \tau_{t+1}+\frac{n}{R} \tau_{t+2}\right)\right)_{(8)}}{R} \\
v^{o, j}\left(h_{t-1}^{u}, \tau_{t}, \tau_{t+1}\right) & =n \tau_{t}\left(\frac{h_{t-1}^{u}}{w^{u}}+n\left(1-\tau_{t}+\frac{1-\tau_{t+1}}{R}\right)\right)
\end{aligned}
$$

Note that $v^{o, s}=v^{o, u}$ since social security benefit $p_{t+1}$ are evenly distributed across retirees.

\subsection{Ramsey Allocation}

In this subsection, we characterize the Ramsey allocation in which a utilitarian planner with a commitment technology sets the sequence of tax rates $\left\{\tau_{t}\right\}_{t=0}^{\infty}$ so as to maximize a social welfare function. Our purpose is twofold. First, we show that under the linear quadratic utility, wage inequality has no effect on the steady-state tax rate; nor does it affect taxes along the transition path to the steady state. Second, due to tax distortion, it is optimal to eliminate social security in the long run if the economy satisfies the modified Golden Rule. Accordingly, our model shares the same normative implication for the efficiency of social security as the standard theory has.

\footnotetext{
${ }^{16}$ Alternatively, we can normalize the average wage rate to unity by letting $w^{s}=\left(1-\lambda w^{u}\right) /(1-\lambda)$. This leads to no major change in the following results.
} 
Specifically, we assume that there is a planner maximizing the sum of the discounted utilities of all generations with a social discount factor $\beta$. We also assume that $\tau_{t}$ cannot exceed $\bar{\tau} \leq 1$, but can be negative. The negative $\tau_{t}$ refers to the redistribution from retirees to working generations. Appendix 7.1 specifies the Ramsey problem and characterizes the solution. An immediate finding is that the linearity of utility over consumption gives the planner no incentive for intra-generational redistribution. This explains why tax is independent of wage inequality in the Ramsey allocation, both at the steady state and along the transitional path.

It is also instructive to see the normative implications of the model in a special case with $\beta=n / R$. The condition, often labeled as the modified Golden Rule, implies that the planner weighs generations by their relative sizes and discounts their welfare by the interest rate. In Appendix 7.1, we prove that the tax rate converges to zero. The intuition is simple. At the steady state, the marginal rate of substitution of the planner between consumption of two consecutive generations, $\beta R$, is already equal to the marginal rate of transformation $n$. So, there is no further room for inter-generational redistribution. In addition, the linearity of preference over consumption implies no need for intra-generational redistribution. Therefore, given the presence of tax distortions, it is optimal not to impose a positive social security tax in the long run. ${ }^{17}$

In short, we show that wage inequality does not affect the social security tax if there is a benevolent planner, and the normative implications of our model economy are in line with those in the existing literature. This warm-up exercise indicates that the sustainability and the effect of wage inequality on social security in political equilibrium, as will be shown below, stem from a lack of commitment and conflicts of interests across different groups of individuals.

\section{Political Equilibrium}

In this section, we characterize the political equilibrium, in which the social security tax rate $\tau_{t}$ is determined by some political decision process at any time $t .{ }^{18}$ The set of equilibria, as equilibria of a dynamic game among successive generations of voters, is potentially large. We

\footnotetext{
${ }^{17}$ We also discuss a more general case in which $\beta \in[1 / R, n / R]$ in the appendix.

${ }^{18}$ Our model can potentially be extended to allow individuals to vote each period for the degree of actuarial fairness of the system, together with the tax rate. In a similar environment but with only a one-shot game and no intergenerational conflicts, Cremer, Donder, Maldonado and Pestieau (2007) show that given the poor as the median voter, a non-actuarially fair social security system (Beveridgean system) will be chosen if all voters are either far-sighted or myopic, or there is perfect substitutability of consumption across periods. This is because, compared to an actuarially fair system (Bismarckian system), the redistributive benefit from a Beveridgean system dominates its distortion on labor supply. Therefore, our conjecture is that a non-actuarially fair system will be chosen each period in our economy, in which all individuals are far-sighted, and there is perfect substutability of consumption across periods in utility.
} 
restrict attention to Markov perfect equilibria, where $\tau_{t}$ follows a policy rule $T$ contingent on payoff-relevant state variables. For analytical convenience, we further assume $T$ to be continuous and differentiable. The corresponding equilibrium is referred to as the differentiable Markov perfect equilibrium (DMPE henceforth). ${ }^{19}$

\subsection{Differentiable Markov Perfect Equilibrium}

There are two state variables at time $t$, human-capital stock $h_{t-1}^{s}$ and $h_{t-1}^{u}$. Since $h_{t-1}^{s} / h_{t-1}^{u}=$ $w^{s} / w^{u}$, we can, without loss of generality, confine the payoff-relevant state variable to $h_{t-1}^{u}$. The Markovian policy rule $T$ can, thus, be written as as a function of $h_{t-1}^{u}$ only:

$$
\tau=T\left(h_{-1}^{u}\right)
$$

where $T:[\underline{h}, \bar{h}] \rightarrow[\underline{\tau}, \bar{\tau}], \underline{h} \equiv w^{u}(1+1 / R)(1-\bar{\tau})$ and $\bar{h} \equiv w^{u}(1+1 / R)(1-\underline{\tau})$ are the lower and upper bound of $h_{-1}^{u}$, respectively. We drop time subscript when there is no source of confusion. Let $\bar{\tau} \leq 1$ and $\underline{\tau}<0$, as in the Ramsey solution. Plugging (10) into (3) with $j=u$, we have

$$
h^{u}=w^{u}\left(1-\tau+\frac{1-T\left(h^{u}\right)}{R}\right) .
$$

Given $T$, equation (11) solves the human capital investment decision of the young poor $H$ : $[\underline{\tau}, \bar{\tau}] \rightarrow[\underline{h}, \bar{h}]$.

A combination of $T$ and $H$ yields

$$
\tau^{\prime}=T \circ H(\tau) \equiv B(\tau)
$$

where $B:[\underline{\tau}, \bar{\tau}] \rightarrow[\underline{\tau}, \bar{\tau}]$, representing an intertemporal policy rule that links the future tax to the current one. The intertemporal tax linkage, endogenously obtained by the joint of the Markovian tax rule and the private investment decision, will serve as the cornerstone of our analysis below.

The presence of the intertemporal tax linkage allows the current policy decision maker to indirectly influence future political decisions. Although there is no commitment to future policy outcomes, private investment provides a channel through which $\tau$ can influence $\tau^{\prime}$. Moreover, the derivative of $B$ captures the degree to which the future tax responds to the current one:

$$
B^{\prime}(\tau)=T^{\prime}(H(\tau)) H^{\prime}(\tau) .
$$

\footnotetext{
${ }^{19}$ The assumption of differentiability has often been adopted in recent studies on social security (e.g., Azariadis and Galasso, 2002, Forni, 2005) and fiscal policy (e.g., Klein, Krusell and Rios-Rull, 2008, Azzimonti Renzo, 2005). Krusell and Smith (2003) show that there could be, in principle, an infinitely large number of nondifferentiable Markov equilibria. Markov Equilibria with non-differentiable strategies may exist in our model. We will, however, not attempt to characterize such equilibria.
} 
We refer to $B^{\prime}(\cdot)$ as the magnitude of the intertemporal tax linkage. Clearly, the larger is $B^{\prime}(\cdot)$, the more easily the current tax can influence the future one. In the extreme case where $B^{\prime}(\cdot)=0$, there is no access for current voters to affect future legislation.

Now we specify the political decision process. Consider a Downsian electoral competition in which there are two candidates (or parties) with the aim of winning the election. ${ }^{20}$ The political choice on $\tau$ solves

$$
\tau=\arg \max _{\tau \in[\tau, \bar{\tau}]} v^{d e c}
$$

subject to $\tau^{\prime}=B(\tau) . v^{d e c}$ is the indirect utility function of the decisive voter. For analytical simplicity, we assume that young agents do not vote. This assumption can be rationalized by the fact that the older generations are more influential in the determination of public policies. ${ }^{21}$

(8) and (9) show that the political choice of $\tau$ depends only on $h_{-1}^{u}$, irrespective of which group is decisive. Define $\tau=\tilde{T}\left(h_{-1}^{u}\right)$ as the solution of (14). $T$ is an equilibrium policy rule if and only if $T=\tilde{T}$. The definition of the equilibrium is given by

Definition 1 A differentiable Markov perfect political equilibrium (DMPE) is a pair of differentiable functions $\langle T, H\rangle$, where $T:[\underline{h}, \bar{h}] \rightarrow[\underline{\tau}, \bar{\tau}]$ is the policy rule of the social security tax rate and $H:[\underline{\tau}, \bar{\tau}] \rightarrow[\underline{h}, \bar{h}]$ is a private decision rule of human-capital investment. $T$ and $H$ solve the following functional equations:

(1) $T\left(h_{-1}^{u}\right)=\arg \max _{\tau \in[\tau, \bar{\tau}]} v^{\text {dev }}$, subject to $\tau^{\prime}=(T \circ H)(\tau)$.

(2) $H(\tau)=w^{u}\left(1-\tau+\frac{1-T \circ H(\tau)}{R}\right)$.

\subsection{The Median Voter}

This subsection shows that the median voter is always the middle poor in our model economy. Before proceeding, it is worth pointing out that the strategic interaction between private intertemporal choice and policy decisions can, in principle, switch the identity of the median voter over time. The dynamic politico-economic equilibrium is, hence, very hard to characterize (the exceptions are Hassler et al., 2003 and Hassler et al., 2007). Nevertheless, since we focus on DMPE, the differentiability helps to rule out the time-varying identity of the median voter and, hence, makes the analysis substantially simpler. ${ }^{22}$

\footnotetext{
${ }^{20}$ See, for example, Chapter 2 of Persson and Tabellini (2000).

${ }^{21}$ For instance, Mulligan and Sala-i-Martin (1999) argue that the old have more influence in the political decision process because they have a lower time cost. Empirically, voting turnout is indeed lower for younger households (e.g., Wolfinger and Rosenstone, 1980). See Hassler et al. (2003) for further discussion.

${ }^{22}$ Song $(2005$, chapter 4$)$ proves that the identity of the median voter is constant over time in DMPE. The intuition is as follows. When the identity of the median voter changes over time, we will observe different political regimes in equilibrium. This leads to a discontinuous or non-differentiable policy rule $T$. Therefore, the technical restriction that the policy function must be differentiable actually amounts to imposing a constant
} 
In the following analysis, we first propose that the middle poor are decisive, and then check the validity of this assumption. Let $\tau^{m, s}, \tau^{m, u}$ and $\tau^{o}$ be the preferred tax rate of the middle rich, the middle poor and the old, respectively, under the expectation that the middle poor will be decisive in the future. Given the majority of the middle-aged among voters and the majority of the poor within the cohort, the following condition is sufficient for the middle poor to be the median voter:

$$
\tau^{m, s} \leq \tau^{m, u} \leq \tau^{o}
$$

for any $h_{-1}^{u} \in[\underline{h}, \bar{h}]$. The first inequality is straightforward. Since the middle rich receive the same social security benefit as the middle poor while paying more taxes, they always prefer a lower tax rate than the middle poor. So, we only need to check the second inequality in (15). We will show in Section 3.4 below that $\tau^{m, u} \leq \tau^{o}$ holds for a wide range of parameter values. The intuition is simple. The middle-aged, as taxpayers, prefer a lower tax rate than the old, who bear no tax burden. ${ }^{23}$

\subsection{Political Choice}

We now investigate how the tax rate is chosen by the middle poor. It immediately follows that $T\left(h^{u}\right)=0$ for all $h^{u} \in[\underline{h}, \bar{h}]$ trivially satisfies the conditions in Definition 1 and (15). To avoid the uninteresting result, we focus on equilibria in which $T\left(h^{u}\right) \neq 0$ at least for some $h^{u} \in[\underline{h}, \bar{h}]$.

For notational convenience, we write the future tax base (6) in a recursive formulation.

$$
y^{\prime}=Y(\tau) \equiv \Pi-n\left(\tau+\left(n+\frac{1}{R}\right) B(\tau)+\frac{n}{R} B(B(\tau))\right) .
$$

Differentiating $Y(\tau)$ yields that $Y^{\prime}(\tau)=-n\left(1+(n+1 / R) B^{\prime}(\tau)+n\left(B^{\prime}(\tau)\right)^{2} / R\right)<0$, irrespective of the value of $B^{\prime}(\tau)$. That is to say, increasing $\tau$ always reduces the future tax base for social security benefit payment.

The tax choice of the middle poor can, thus, be expressed as

$$
\max _{\tau \in[\tau, \bar{\tau}]}(1-\tau) w^{u} h_{-1}^{u}+\frac{1}{R} B(\tau) Y(\tau) .
$$

The first term in the objective function is the after-tax wage incomes, and the second term represents the discounted future benefit from social security. The first-order condition is

$$
w^{u} h_{-1}^{u}=\frac{1}{R}\left(B^{\prime}(\tau) Y(\tau)+B(\tau) Y^{\prime}(\tau)\right)
$$

identity of the decisive voters over time.

${ }^{23}$ Moreover, the current tax base $y$ for redistribution towards the old is less elastic with respect to $\tau$ than the future tax base $y^{\prime}$ for redistribution towards the current middle-aged. 
where the LHS (RHS) of (18) captures the marginal cost (benefit) of taxation for the middle poor. According to (18), the middle poor choose a tax rate so as to trade off their current tax burden against their future redistributive benefit. We suppress two multipliers associated with the constraints $\tau \geq \underline{\tau}$ and $\tau \leq \bar{\tau}$ since corner solutions have been ruled out by the differentiability of $T(\cdot) \cdot{ }^{24}$

Equation (18) reveals both the necessary conditions for the sustainability of social security and the determinants of its size. First, as $Y^{\prime}(\cdot)<0$, one can see from (18) that $B^{\prime}(\cdot)>0$ is necessary for $\tau>\underline{\tau}$. As taxpayers, the middle poor would vote for the lowest tax rate on themselves, if future benefit were independent of or even negatively correlated with their contribution. Hence, a positive intertemporal tax linkage is a prerequisite for sustaining social security. ${ }^{25}$

To better understand the determinants of the size of social security, we make a slight rearrangement of (18).

$$
\begin{aligned}
B(\tau) & =\frac{B^{\prime}(\tau) Y(\tau) / R-w^{u} h_{-1}^{u}}{-Y^{\prime}(\tau) / R} \\
& =\frac{1}{-Y^{\prime}(\tau) / R}(\underbrace{B^{\prime}(\tau) Y(\tau) / R-\overline{w h}_{-1}}_{\text {inter-generational redistribution }}+\underbrace{\overline{w h}}_{\text {intra-generational redistribution }})
\end{aligned}
$$

where $\overline{w h}_{-1} \equiv \lambda w^{u} h_{-1}^{u}+(1-\lambda) w^{s} h_{-1}^{s}=1-\tau_{-1}+(1-\tau) / R$ is the average wage income of the cohort born at time $t-1$. The positive intertemporal tax linkage, which is necessary for sustaining social security, implies that the LHS of (19) is increasing in $\tau$. A special case for (19) is its steady-state formulation, where $B(\tau)=\tau$. Hence, this rearrangement allows us to focus on those governing the magnitude of the RHS as the determinants of social security size.

The second equality in (19) demonstrates that social security benefit can be decomposed into two parts. The first is an inter-generational redistributive component, as represented by $B^{\prime}(\tau) Y(\tau) / R-\overline{w h}_{-1}$. More precisely, this term reflects the marginal future social security benefit for the middle-aged with respect to the current tax, if there is no intra-generational inequality. Notably, the marginal inter-generational redistributive benefit is increasing in $B^{\prime}(\cdot)$, the magnitude of the intertemporal tax linkage. This is because, given a marginal increase

\footnotetext{
${ }^{24}$ If the constraints are binding for some $h_{-1}^{u} \in(\underline{h}, \bar{h})$, then $\tau$ must be equal to 0 or $\bar{\tau}$ for all $h_{-1}^{u} \in[\underline{h}, \bar{h}]$ by the differentiability of $T$. If $T(\cdot)=\bar{\tau}, B^{\prime}(\cdot)=0$. Then (18) implies that $\tau=0$. Contradiction. $T(\cdot)=0$, on the other hand, is a trivial equilibrium.

${ }^{25}$ A special case is that $B^{\prime}(\tau)=1$. Then, the economy essentially goes back to the case of once-and-for-allvoting or trigger strategies, in the sense that future generations will obey the current choice of tax rate. More generally, $B^{\prime}(\tau)=1$ may be interpreted as the situation in which there is no temporal separation between benefit and contribution (i.e., for each individual both social security contribution and benefit payment occur in the same period).
} 
in the current tax, a higher $B^{\prime}(\cdot)$ yields a higher future tax rate and, therefore, more social security benefit for the current middle-aged. The second part is an intra-generational redistributive component, as represented by $\overline{w h}_{-1}-w^{u} h_{-1}^{u}$. Since social security benefit is uniformly distributed across retirees in our model, the lower are wage incomes of the poor, the more social security redistributes from the rich to the poor.

Now, we investigate the determinants of social security size in order. First of all, (19) implies that $\tau$ is positively affected by $B^{\prime}(\tau)$ and $Y(\tau)$. This is because a larger magnitude of the intertemporal tax linkage, $B^{\prime}(\tau)$, or a larger future tax base, $Y(\tau)$, implies more intergenerational redistributive benefit for the middle-aged. In addition, a larger tax distortion $Y^{\prime}(\tau)$ tends to decrease $\tau$. This effect shows up in many standard static or dynamic models

(e.g., Metzler and Richard, 1981, and Krusell and Rios-Rull, 1999). Furthermore, given a positive $B^{\prime}(\tau), \tau$ is increasing in wage inequality, as the standard theory predicts. A larger wage inequality yields a lower pretax income for the middle poor, $w^{u} h^{u}$. The lower marginal cost of taxation leads to a stronger redistributive incentive and, therefore, a higher tax rate today. Note that previous studies often resort to some exogenous intertemporal policy rules (i.e., $B^{\prime}(\tau)$ is given as a parameter), such as reputation mechanism or once-and-for-all voting, to sustain social security. Our analysis above shows that these studies imply a positive correlation between wage inequality and the size of social security, which, as we discuss later, is counterfactual.

In brief, we have shown that a positive intertemporal tax linkage is crucial for the political sustainability of social security. Another important finding is that the magnitude of the intertemporal tax linkage affects the inter-generational redistributive benefit for the decisive voter and, therefore, the political choice on social security size. Now, we would like to characterize analytically this intertemporal policy linkage, as well as the corresponding equilibrium outcomes.

\subsection{Equilibrium Policy Rules}

In this section, we provide sufficient conditions for the existence of DMPE and then characterize the equilibrium. Thanks to the quasi-linear preference, closed-form solutions for equilibrium policy rules can easily be obtained.

Proposition 1 Assume that

$$
\begin{aligned}
& \phi_{0}+\phi_{1} \bar{h} \geq \underline{\tau}, \\
& \phi_{0}+\phi_{1} \underline{h} \leq \bar{\tau},
\end{aligned}
$$


and

$$
\phi_{0}+\phi_{1} \underline{h} \leq \frac{1+\left(1-b_{0}\right) / R+\underline{h} /\left(n w^{u}\right)}{2\left(1+b_{1} / R\right)},
$$

where $b_{1}>0, \pi_{0}>0, \pi_{1}<0, \phi_{0} \equiv-\left(b_{1} \pi_{0}+b_{0} \pi_{1}\right) /\left(2 b_{1} \pi_{1}\right)>0$ and $\phi_{1} \equiv R w^{u} /\left(2 b_{1} \pi_{1}\right)<0$ (see the appendix for the definition of $b_{0}, b_{1}, \pi_{0}$ and $\pi_{1}$ ). Then, there exists a DMPE such that the middle poor is the median voter and

$$
\begin{aligned}
T\left(h_{-1}^{u}\right) & =\phi_{0}+\phi_{1} h_{-1}^{u}, \\
H(\tau) & =h_{0}+h_{1} \tau, \\
B(\tau) & =b_{0}+b_{1} \tau, \\
Y(\tau) & =\pi_{0}+\pi_{1} \tau,
\end{aligned}
$$

where $h_{0}=\frac{w^{u}}{1+w^{u} \phi_{1} / R}\left(1+\frac{1-\phi_{0}}{R}\right)>0, h_{1}=-\frac{w^{u}}{1+w^{u} \phi_{1} / R}<0$.

Proof. See the appendix.

The first part of the proposition describes technical assumptions for the existence of a DMPE, in which the middle poor are always the median voter. (20) and (21) are assumptions to ensure interior solutions, i.e., $T\left(h_{-1}^{u}\right) \in[\underline{\tau}, \bar{\tau}]$ for any $h_{-1}^{u} \in[\underline{h}, \bar{h}] .^{26}(22)$ is a sufficient condition for the second inequality in (15) to be satisfied, i.e., the old always prefer a higher tax rate than the middle poor. In other words, this assumption makes sure that the middle poor are always the decisive voter. ${ }^{27}$ Therefore, if $\underline{\tau}=0$, an economy satisfying these assumptions can sustain social security in a DMPE.

(20), (21) and (22) can be met under a wide variety of combinations of $n$ and $w^{u}$. A numerical example is plotted in Figure 1, where we set $R=1.025^{30}, \lambda=0.5, \underline{\tau}=0$ and $\bar{\tau}=0.9$. Condition (21) fails to hold only for very large values of $n$ (e.g., $n>20$ outside the range in the figure). (20) holds for all $w^{u}$ and $n$ in the diagram of Figure 1, except the triangle with high $w^{u}$ and low $n$. The dotted line in the graph plots the threshold condition of $n$ implied by (22), which is satisfied for any $n$ above the line. One can directly see that (22) also holds for a large set of $w^{u}$ and $n$. An immediate observation is that social security can be sustained in a dynamic efficient economy $(R>n)$, as long as wage inequality is not too low, i.e., $w^{u}$ is not too high. Intuitively, the political sustainability of social security originates from both inter-generational and intra-generational redistributive incentives. In a more unequal society, the poor are more willing to support social security for intra-generational redistribution.

\footnotetext{
${ }^{26}$ Given (20), the middle poor would like to choose tax rates higher than $\underline{\tau}$ for any $h_{t-1} \in[\underline{h}, \bar{h}]$. (21) ensures that $\tau_{t} \leq \bar{\tau}$ is not binding. Since $T^{\prime}(\cdot)<0$, the minimum (maximum) value of $\tau_{t}$ is located at $h_{t-1}=\bar{h}(\underline{h})$.

${ }^{27}$ Note that $(22)$ is more likely to hold by a higher $\underline{h}$ (or a lower $\bar{\tau}$ ). This is because $\tau^{m, u}$ decreases in $h_{-1}$, while the old tend to impose a higher tax rate with a larger inelastic human capital stock $h_{-1}$.
} 


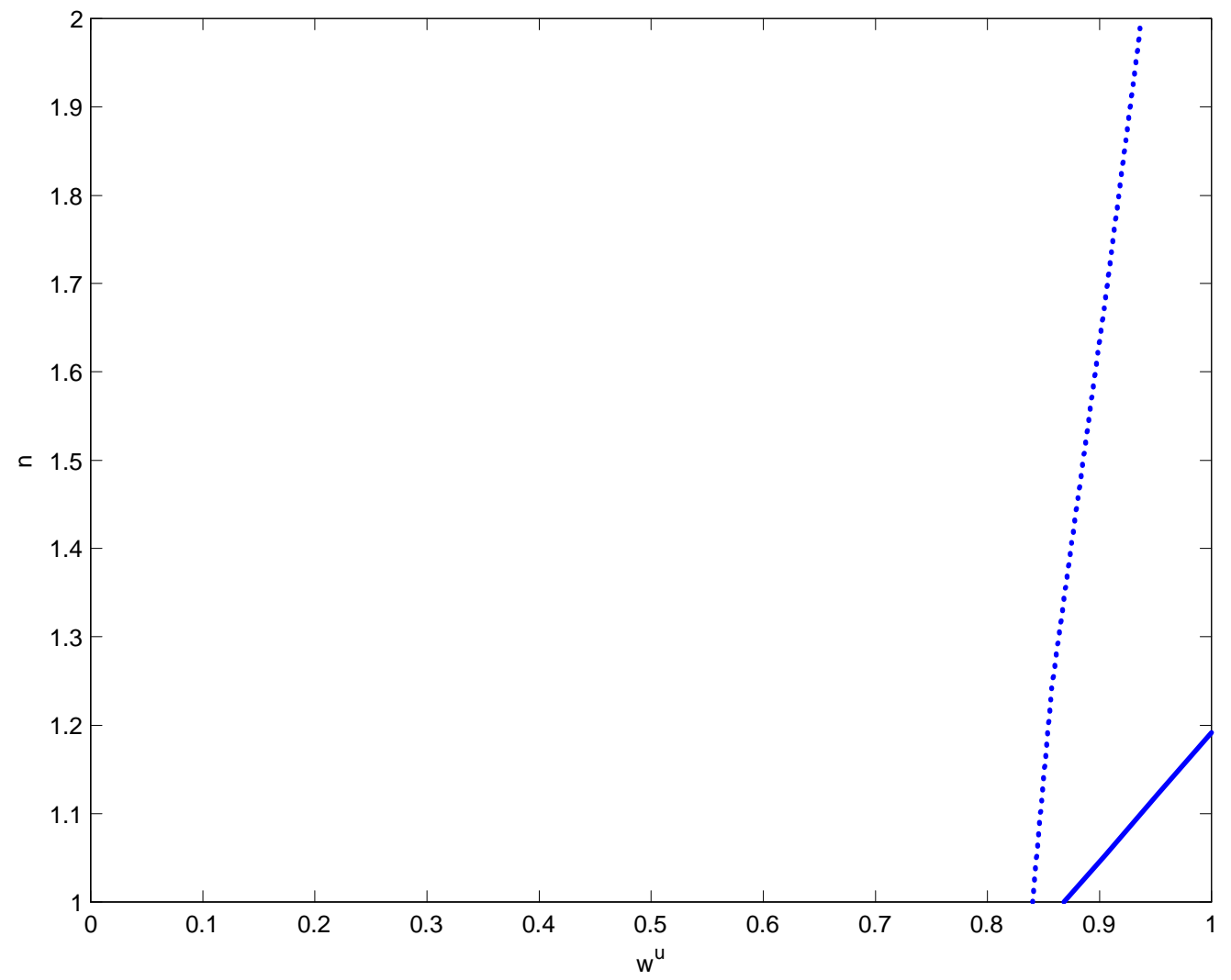

Figure 1: Range of Population Growth Rate and Wage Inequality for Political Sustainability of Social Security

The second part of the proposition characterizes our DMPE. First of all, both $\phi_{1}$ and $h_{1}$ are negative. The negative $h_{1}$ or $H^{\prime}(\cdot)$ is straight forward: A distortionary tax discourages human-capital investment. Also, the negative $\phi_{1}$ or $T^{\prime}(\cdot)$ simply results from the fact that the human-capital stock of the middle poor negatively affects their future social security benefit and, therefore, their tax choice.

The combination of $H^{\prime}(\cdot)<0$ and $T^{\prime}(\cdot)<0$ establishes our positive intertemporal tax linkage, the cornerstone for the political sustainability of social security in our model economy. To see the underlying politico-economic mechanism more clearly, consider an increase in today's tax rate. $H^{\prime}(\cdot)<0$ leads to a lower human-capital investment of the young. Then $T^{\prime}(\cdot)<0$ implies a higher tax rate tomorrow due to more redistributive benefit for tomorrow's decisive voters (the current young). Rationally perceiving the linkage, the current middle poor understand that the more taxes they pay today, the more social security benefit they will receive tomorrow. This provides the incentive for the current middle poor to choose a positive tax rate. 
The following corollary characterizes the dynamics of the size of social security.

Corollary 1 Let $\underline{\tau}=0$ and assume (20), (21) and (22). In the DMPE, we have $b_{0} \geq 0$ and $b_{0} /\left(1-b_{1}\right) \in[0, \bar{\tau}]$. The social security tax rates monotonically converge to the steady state $b_{0} /\left(1-b_{1}\right)$.

Proof. See the appendix.

Suppose that the political decision process on social security occurs unanticipatedly at time 0 . Then, the above corollary predicts an increasing sequence of social security tax rates over time, which converge to the steady state rate $b_{0} /\left(1-b_{1}\right)$. To see this, note that the middle poor at time 0 invested more in human capital than the middle poor in subsequent periods, due to an expectation of zero taxes before time 0 . Consequently, the initial tax rate chosen by the initial middle poor is actually the lowest in the dynamics. Moreover, the initial positive tax distorts the human-capital investment of the second-period middle poor so that they end up with less human capital than the initial-period middle poor. This encourages them to choose a tax rate higher than the initial one. A similar argument applies to the political choice afterwards and, thus, explains why tax rates in later periods increase monotonically towards a steady state.

Finally, it is worth mentioning that the DMPE characterized by Proposition 1 is determinate. ${ }^{28}$ This contrasts sharply with the indeterminacy of linear Markov equilibria in Azariadis and Galasso (2002), though their model has a number of common features with ours (e.g., the linear technology, the temporal separation of contribution and benefit and a lack of commitment). The reason is that, in their model, the political sustainability relies solely on a selffulfilling expectation of future social security benefit that is independent of politico-economic fundamentals. ${ }^{29}$ By contrast, the political choice in our model depends on human capital stock $h_{-1}^{u}$, which is indeed payoff-relevant for the policy decision maker. Such a Markovian policy rule excludes the indeterminacy of equilibria. Therefore, our model can deliver testable implications for the correlation between wage inequality and the size of social security, as we will

\footnotetext{
${ }^{28}$ Although we cannot analytically rule out nonlinear solutions, numerical simulations show that the equilibrium strategy in a space of nonlinear functions indeed converges to the linear one (23). The computational strategy adopts a standard projection method with Chebyshev collocation (Judd, 1992), to approximate the equilibrium strategy on the basis of a high-order polynomial functional space.

${ }^{29}$ Azariadis and Galasso (2002) find indeterminate equilibria in which the young, as the median voter, conditions their voting choices on the capital stock of the old. However, in their two-period OG model with linear technology, capital held by the old is payoff-irrelevant for the young median voter. A related but somewhat different problem can also be found in Forni (2005), which uses capital as the state in a general equilibrium framework. In his model, capital per se does not affect the median voter's tax choices due to the log utility specification. Consequently, current capital stock affects the current policy choice if and only if the current median voter expects that the choice of the next-period tax rate relies on the next-period capital stock.
} 
show in the next section.

\section{Effects of Wage Inequality}

Now, we would like to address the second key question of this paper: how wage inequality affects the size of social security, in both the short run and the long run. The answer to this question provides testable implications, which can be confronted with the empirical observations. Our analysis takes two steps. First, we explore the potential channels for wage inequality to affect tax choice. In particular, we identify two opposite effects of wage inequality on the size of social security. We then ask how wage inequality affects tax choice through these two effects.

\subsection{The Strategic Effect and the Redistributive Effect}

It is useful to define a benchmark social security tax rate:

$$
\hat{\tau} \equiv \phi_{0}+\phi_{1} \hat{h}^{u}
$$

where $\widehat{h}^{u}=w^{u}(1+1 / R)$ is the first-best human capital stock of the middle poor. We refer to $\hat{\tau}$ as the "baseline tax rate". $\hat{\tau}$ is the minimum tax rate implied by the Markovian tax rule $T$ when $\underline{\tau}=0 .{ }^{30}$ Later on, we will show that the actual tax rate in the steady state is equal to the product of the baseline tax rate and a multiplier.

The impact of wage inequality on the baseline tax rate can be expressed as

$$
\frac{\partial \hat{\tau}}{\partial w^{u}}=\underbrace{\frac{\partial \phi_{0}}{\partial w^{u}}+\frac{\partial \phi_{1}}{\partial w^{u}} \widehat{h}^{u}}_{\text {the strategic effect }}+\underbrace{\phi_{1} \frac{\partial \widehat{h}^{u}}{\partial w^{u}}}_{\text {the redistributive effect }}
$$

Equation (28) shows that wage inequality affects the baseline tax rate $\hat{\tau}$ through two channels, as represented by the two arguments in the RHS of (28). The first channel is via $\phi_{0}$ and $\phi_{1}$ in the Markovian tax rule $T$, while the second is via its effect on human capital stock.

We first explore the second channel. It is straightforward that $\widehat{h}^{u}$ is increasing in $w^{u}$. Since $\phi_{1}<0$, the positive impact of $w^{u}$ on $\widehat{h}^{u}$ implies that an increase in $w^{u}$ tends to reduce the baseline tax rate. Intuitively, a lower $w^{u}$ yields a lower first-best human-capital investment, which leads to more redistributive benefit and, therefore, a higher preferred tax rate of tomorrow's decisive voters. This is referred to as the "redistributive effect," which has been extensively investigated in the standard politico-economic theory.

The effect of $w^{u}$ through $\phi_{0}$ and $\phi_{1}$, two parameters governing the Markovian tax rule, is a novel feature of our model. This channel actually implies a negative effect of wage inequality on

\footnotetext{
${ }^{30}$ Note that $\widehat{h}^{u}=\bar{h}$ when $\underline{\tau}=0$.
} 
the size of social security. To see this, we first explore the effect of $w^{u}$ on $b_{1}$, a key determinant for inter-generational redistributive benefit. The following lemma reveals a negative correlation between wage inequality and the magnitude of the intertemporal tax linkage $b_{1}$.

Lemma 1 Assume (20), (21) and (22). Then, $\partial b_{1} / \partial w^{u}>0$.

Proof. See the appendix.

A larger wage inequality lowers the absolute value of $h_{1}$, as the relatively lower wage rate for the poor dampens the impact of the current tax on human-capital investment of the young poor. This is the first-order effect of $w^{u}$ on $b_{1}$, resulting in a weakened intertemporal tax linkage. Therefore, Lemma 1 establishes a negative effect of wage inequality on $b_{1}$ and, hence, on the inter-generational redistributive benefit illustrated in (19). The above lemma helps to explain how the Markovian tax rule $T$ responds to a change of $w^{u}$.

Proposition 2 Assume (20), (21) and (22). Then, $\partial \phi_{0} / \partial w^{u}>0$ and $\partial \phi_{1} / \partial w^{u}>0$.

Proof. See the appendix.

Proposition 2, together with equation (27), shows that given human-capital stock $h_{-1}^{u}$, wage inequality has a negative effect on the choice of $\tau$. This is because an increase in wage inequality can actually reduce inter-generational redistributive benefit for the current policy decision maker by weakening the intertemporal tax linkage. Anticipating this, she will therefore choose a lower tax. We label this negative impact of wage inequality on $\tau$ via equilibrium policy rules, captured by $\phi_{0}$ and $\phi_{1}$ in (28), as the "strategic effect."

The two opposite effects of wage inequality make the sign of $\partial \hat{\tau} / \partial w^{u}$ ambiguous. In (28), the first argument is positive due to the positive effect of $w^{u}$ on $\phi_{0}$ and $\phi_{1}$. By contrast, the second argument is negative since $\phi_{1}<0$. As Panel A of Figure 2 shows, $\hat{\tau}$ is hump-shaped in $w^{u} \cdot{ }^{31}$ In other words, when wage inequality is sufficiently large, there exists a negative relationship between wage inequality and the baseline tax rate. Only after inequality falls below some critical level does the correlation between inequality and the baseline tax rate become positive. Panel B of Figure 2 plots the relative magnitude of the two effects for different levels of wage inequality. We see that when $w^{u}$ is small, the magnitude of the strategic effect is large and dominates the redistributive effect. As $w^{u}$ keeps increasing, the strategic effect becomes smaller. This is because the current tax becomes more distortionary via a larger $b_{1}$ : An increase of today's tax leads to a larger increase of tomorrow's tax, which distorts further the current human-capital investment. Consequently, the redistributive effect starts to dominate when $w^{u}$ becomes sufficiently large.

\footnotetext{
${ }^{31}$ We set $R=1.025^{30}, \lambda=0.5$ and $n=1.38$ in Figure 2.
} 

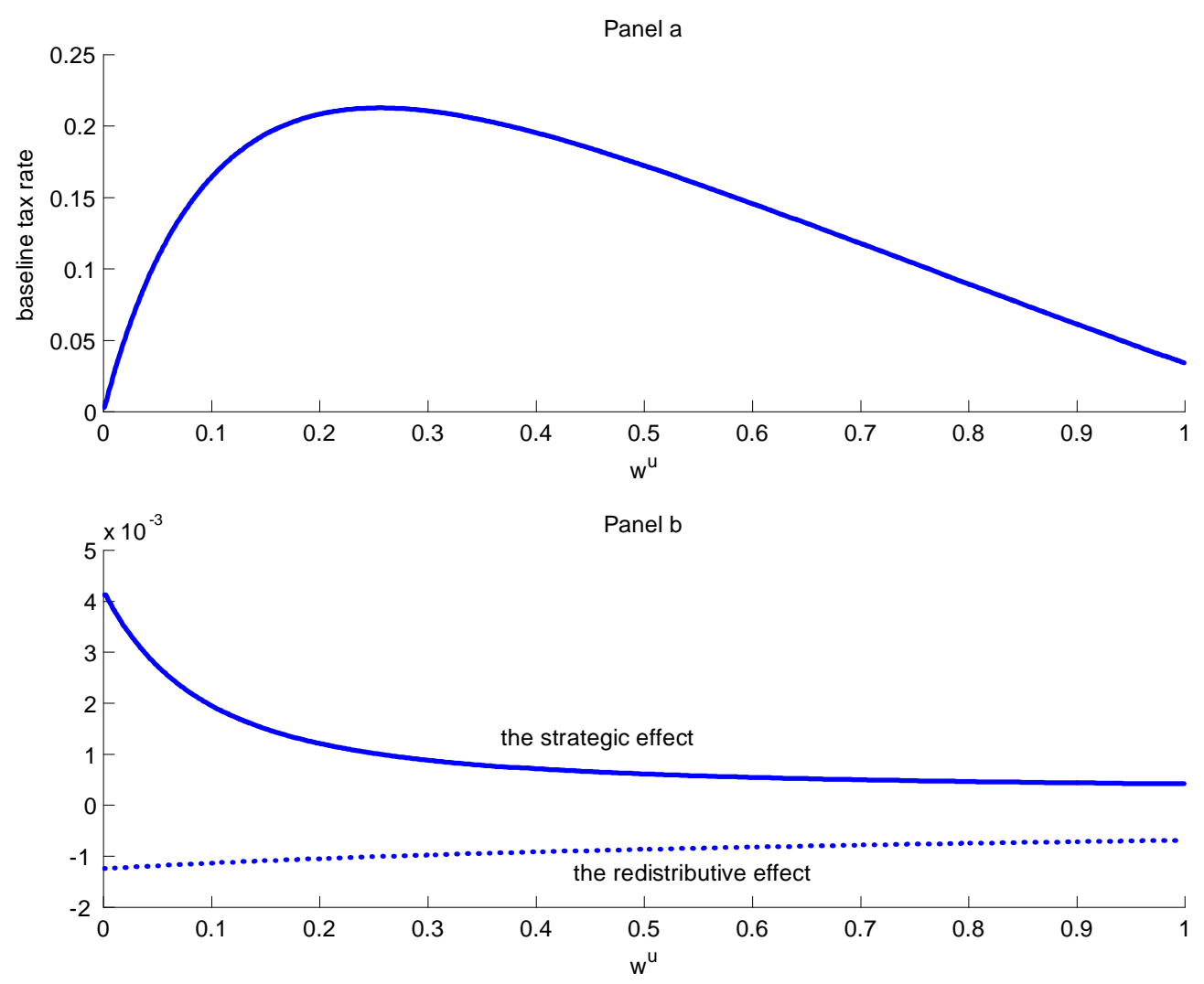

Figure 2: The Strategic and the Redistributive Effects on the Baseline Tax Rate

\subsection{Permanent Shock to Wage Inequality}

Our strategic effect generates some novel predictions regarding the impacts of wage inequality on the size of social security. We first investigate how permanent shocks to wage inequality affect the secular movement of social security size. Since the human-capital stock of the middle poor is predetermined, the redistributive effect of shocks to wage inequality is shut down upon impact. In other words, only the strategic effect plays a role when such a shock hits the economy.

Let us consider a permanent increase in wage inequality. Our experiment is as follows. Suppose that the economy is at the steady state in period 0. At the beginning of period 1, there is an unexpected increase in wage inequality. It is followed by the political decision process on $\tau$ at time 1 . Figure 3 plots the transition path with the permanent shock to wage inequality. ${ }^{32}$ We see that the tax rate drops sharply following a widening of the wage gap and, then, gradually increases towards a new steady state, the level of which will be discussed

\footnotetext{
${ }^{32}$ In Figure 3, we set $R=1.025^{30}, \lambda=0.5, n=1.38, w^{u}=0.4$ and 0.36 before and after the shock.
} 
below. ${ }^{33}$ The intuition is simple. When wage inequality suddenly increases, the middle poor at period 1 will vote for a lower tax rate than that in the initial steady state, as driven by the strategic effect highlighted in (28). Moreover, the young poor at period 1 reduce human-capital investment due to the lower wage rate. ${ }^{34}$ The lower human-capital stock will then encourage the middle poor at period 2 to choose a higher tax than at period 1 . This will discourage further human-capital investment of the young poor at period 2, which translates into a higher tax rate at period 3 . Similar logic applies to all future periods.

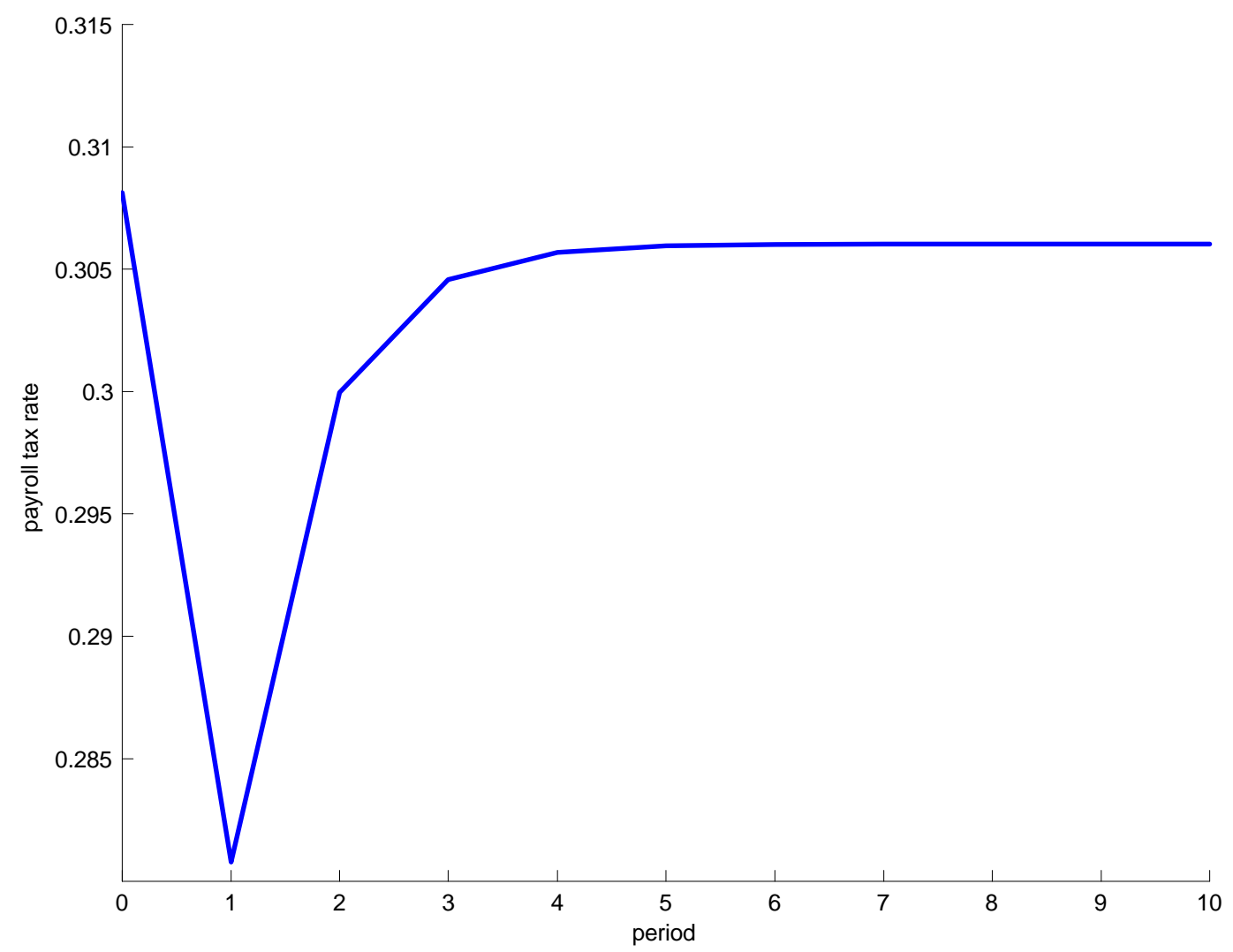

Figure 3: Impulse Response Function for an Unanticipated Permanent Shock to Wage Inequality

\footnotetext{
${ }^{33}$ In fact, there is an overshooting of the tax. In the following section, we will show that the overshooting behavior is consistent with our empirical findings for the U.S. data.

${ }^{34}$ The lower wage rate has a first-order effect on human-capital investment, which dominates the effect of the associated lower tax rate in political equilibrium.
} 


\subsection{The Steady-State Size of Social Security}

We now extend the analysis to the impact of wage inequality on the steady-state tax rate. ${ }^{35}$ The linear intertemporal tax linkage (25) delivers a steady-state tax rate of

$$
\tau^{*} \equiv \frac{b_{0}}{1-b_{1}} .
$$

Note that $b_{0}$ represents the component of the next-period tax that is independent of the current tax. Equation (46) in the appendix shows that

$$
b_{0}=\hat{\tau}\left(1+\frac{b_{1}}{R}\right)
$$

The first component in the RHS of (30) is the baseline tax rate in (27). The second component is a multiplier of the baseline tax rate, representing the repercussions of a future tax on itself via human-capital investment. Specifically, an increase in future taxation distorts human-capital investment today, which translates into a lower human-capital stock and, thus, a higher tax rate tomorrow.

Substituting (30) into (29), we obtain

$$
\tau^{*}=\hat{\tau} \frac{\left(1+b_{1} / R\right)}{1-b_{1}} .
$$

Similar to $b_{0}, \tau^{*}$ can be decomposed into two components. The first component in the RHS of (31) is, again, the baseline tax rate. The second component is a multiplier of the baseline tax rate, representing the repercussions of the current tax on $\tau^{*}$. Specifically, with a positive $b_{1}$, a marginal increase in the current tax leads to a higher future tax rate by discouraging humancapital investment today. The higher future taxation discourages human-capital investment further and, thus, feedbacks into a higher steady-state tax rate.

The overall effects of wage inequality can be decomposed as follows:

$$
\frac{\partial \tau^{*}}{\partial w^{u}}=\frac{\left(1+b_{1} / R\right)}{1-b_{1}} \frac{\partial \hat{\tau}}{\partial w^{u}}+\frac{\hat{\tau}(1+1 / R)}{\left(1-b_{1}\right)^{2}} \frac{\partial b_{1}}{\partial w^{u}} .
$$

The first term in the RHS of (32) captures the effect of $w^{u}$ on the baseline tax rate, and the second term is the effect of $w^{u}$ via the multiplier. The second term is always positive, while the sign of the first term is ambiguous due to the two opposite effects of $w^{u}$ on $\hat{\tau}$. In particular, we find that in our numerical experiments, $\tau^{*}$ is non-monotonically related to $w^{u}$. Figure 4 shows an inverted-U shaped correlation between $w^{u}$ and $\tau^{*} \cdot{ }^{36}$ The hump shape is due primarily to the hump shape of the baseline tax rate depicted in Figure 2. 


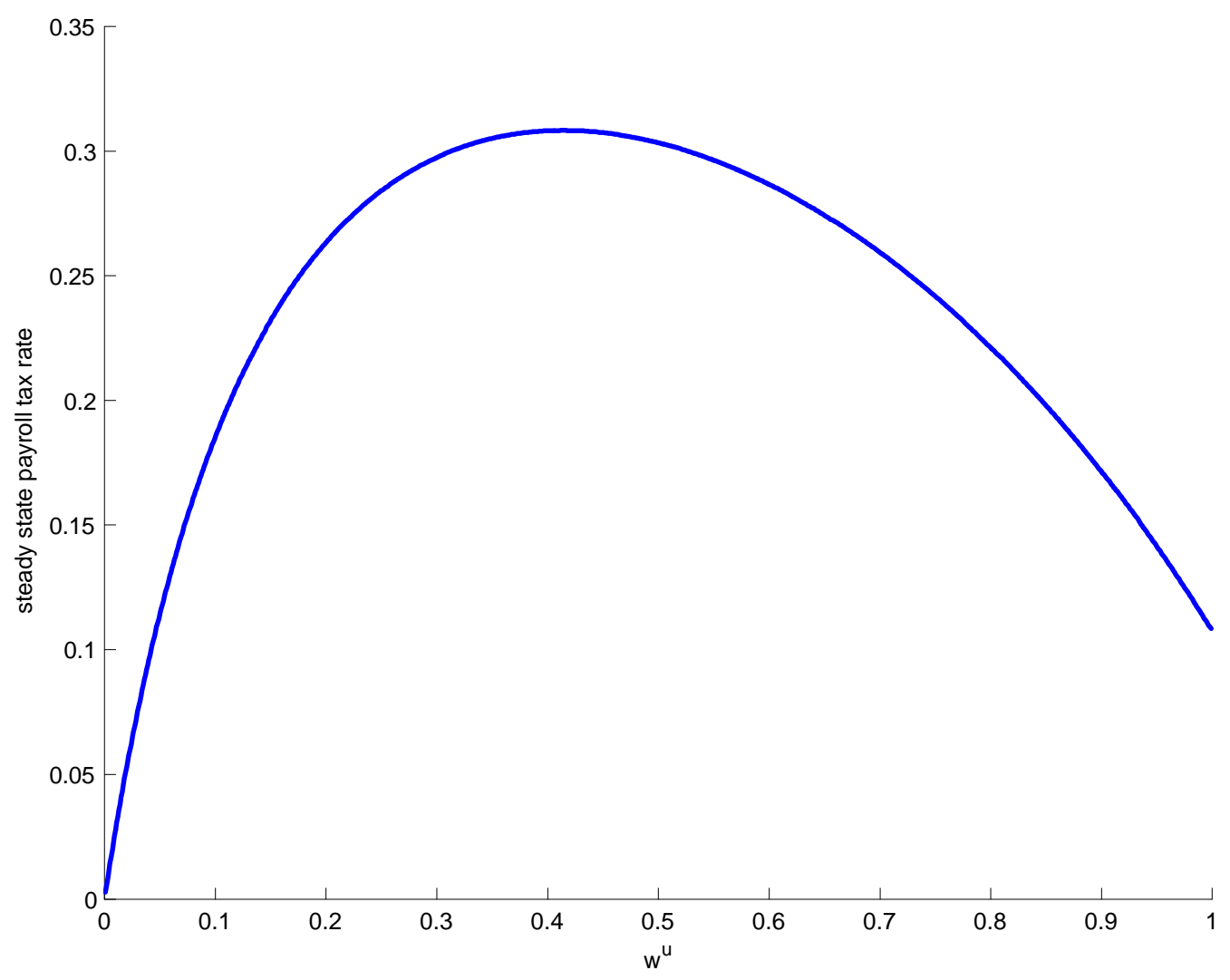

Figure 4: The Correlation between Wage Inequality and Steady-State Payroll Tax Rate

Finally, it is worth mentioning how the demographic structure affects the size of social security in our model. Following the same procedure as in the proof of Lemma 1, one can easily establish that $\partial b_{1} / \partial n<0$. Although similar to a lower $w^{u}$, a larger $n$ weakens the intertemporal tax linkage, it directly increases inter-generational redistributive benefit. Our numerical simulation suggests that the direct effect always dominates the strategic effect via $b_{1}$. Therefore, our model delivers results that are qualitatively similar to those in the standard theory; i.e., a high dependency ratio leads to a larger size of social security.

\section{Empirical Evidence}

Can the above-mentioned theoretical predictions be consistent with the empirical observations? Note that the key element driving our model predictions, the intertemporal tax linkage, also stands as the core to sustain social security in our economy. Therefore, an answer to this ques-

\footnotetext{
${ }^{35}$ Our numerical results show that the channels provided below also apply for tax rates along the transition path.

${ }^{36}$ The parameterization for Figure 4 is the same as for Figure 2.
} 
tion serves as a natural test of our theory versus alternative mechanisms for the sustainability of social security.

In this section, we provide some evidence on the correlations between wage inequality and the size of social security. We first look at the time-series evidence from the U.S. Using cointegration techniques and error-correction models, we find a negative long-run relation in the U.S. Moreover, the size of social security responds negatively to shocks on inequality in the short run. We then look at averaged data on 19 OECD countries from 1980 to 2000 as a further check. Consistent with Perotti (1996) and Lindert (1998), among others, we find no evidence supporting a positive correlation between inequality and redistribution. All of these empirical findings are in line with our model predictions, while it is hard to explain by the standard theory.

\subsection{Time-series Evidence}

For many industrial democracies, earnings inequality featured an upward shift during the 1980s and 1990s, while the size of redistributive programs grew less quickly (see, for example, Persson and Tabellini, 2000). This observation also holds for social security, which is, by far, the largest redistributive program in most OECD countries. In this subsection, we document the time-series evidence from the U.S. during the period from 1963 to 2003, a period for which high-quality data on both earnings inequality and social security are available. ${ }^{37}$

The history of the U.S. social security program can be divided into two periods: an expansionary period lasting about 40 years, followed by a period of contraction. The 1970 s represent a watershed in the program's history. The first large-scale legislative effort to control program size were the 1977 amendments to the Social Security Acts of 1935. From that point forward, social security debates have no longer focused on expanding the program, but on limiting its growth. ${ }^{38}$

We use the data on Old-Age and Survivors Insurance (OASI henceforth) benefit payments as a measure of the size of the U.S. social security program. ${ }^{39}$ Panel A of Figure 5 plots benefit payment as a percentage of GDP ( $S S B$ henceforth). Note that benefit payment peaked in 1982 at about four percent and trended downward thereafter. Similar patterns can be found for the replacement rates - the percentage of earnings replaced by benefit - an indicator that better measures the size of benefit per beneficiary. Martin and Weaver (Chart 5, 2005), for

\footnotetext{
${ }^{37}$ Using both the time-series and cross-state data in the U.S., Rodriguez (1998) found no statistically significant relationship between inequality and redistribution.

${ }^{38}$ See Martin and Weaver (2005) for details on the history of the U.S. Social Security program.

${ }^{39}$ Data for benefit payments are from Table VI.A2 of 2007 OASDI Trustees Report. Data for GDP are from the Bureau of Economic Analysis.
} 
example, show that replacement rates for all types of earners rose through 1981. In particular, the replacement rate for the low earner increased from below 30 percent in 1940 to about 70 percent. But since then, it has trended downward for earners at all levels because of the 1977 amendments.

Panel B of Figure 5 plots the evolution of full-time hourly wage inequality, measured by the ratio of the log median earnings to the upper limit of the log earnings in the 9 th decile of the earnings distribution, denoted by $D 5 / D 1 .^{40}$ We see that wage inequality took off in the late 1970s and kept growing until the mid 1980s. Since then, wage inequality has persistently remained at a high level. ${ }^{41}$ In short, the persistent rise in wage inequality precedes the decline in the size of the social security program, indicating a negative correlation between inequality and social security in the short run.
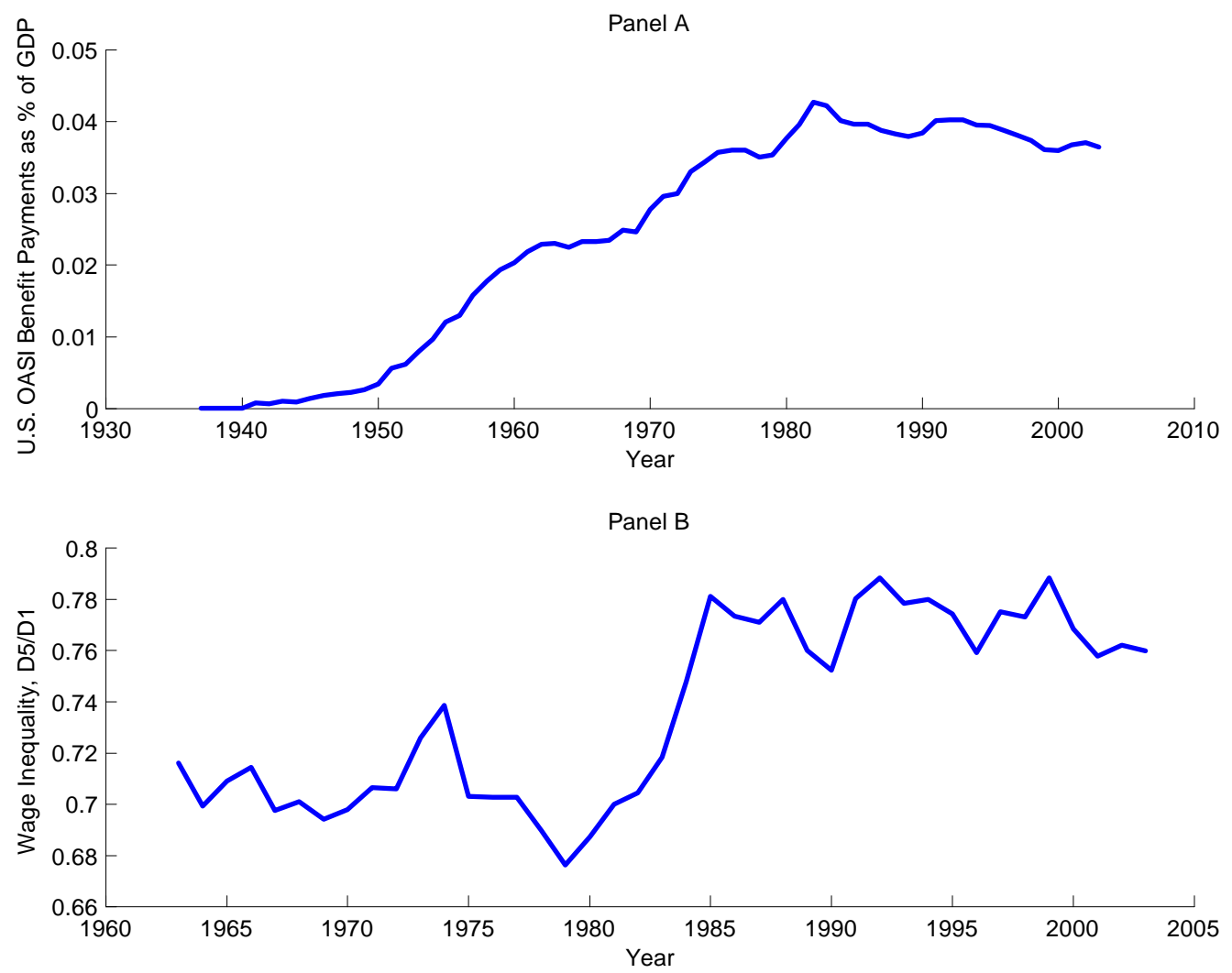

Figure 5: The Evolution of OASI Benefits and Wage Inequality in the U.S.

\footnotetext{
${ }^{40}$ Data for wage inequality are from Autor, Katz and Kearney (2005).

${ }^{41}$ A large literature documents a substantial widening of the U.S. wage structure during the 1980s (e.g., Katz and Murphy, 1992, Juhn, Murphy and Pierce, 1993). One important conclusion reached by this literature is that much of the rise in U.S. earning inequality during the 1980s appears to be explained by shifts in the supply of and demand for skills and, hence, permanent (Autor, Katz and Kearney, 2005).
} 
We establish this negative correlation by a more careful time-series analysis. Social security benefit is closely related to demographic structure. So, we include the dependency ratio ( $D E P$ henceforth) in the analysis. Using cointegration techniques, we find that $D 5 / D 1$ has a significantly negative impact on $S S B$, suggesting a negative long-run correlation between inequality and social security. ${ }^{42}$ The dependency ratio $(D E P)$ is positively correlated with $S S B$, as expected.

We then proceed by estimating vector error correction (VEC) models describing the shortrun dynamics of $S S B$. The results suggest a convergence of $S S B$ to the long-run equilibrium relationship. To see explicitly the short-run dynamics of $S S B$, Figure 6 plots the impulse response function of $S S B$ with respect to a one-percentage increase in wage inequality based on an estimated VEC model. ${ }^{43}$ The figure shows that the rise of wage inequality results in a decline of $S S B$, which peaks in the sixth year after the inequality shock. Consistent with our simulation result in Figure 3, the impulse response of $S S B$ also exhibits overshooting upon the shock to wage inequality. Moreover, the impact of shocks to inequality is quantitatively important in the short run. Note that $D 5 / D 1$ increased by about eight percentage points from the late 1970s to the mid-1980s. According to the estimates in Figure 6, such a shock would cut $S S B$ by 0.3 percent to 0.4 percent in five or six years. This can explain a large share of the observed 0.4 percent to 0.5 percent decline of $S S B$ from 1982 to the late 1980s. The evidence on the short-run impact of permanent shocks to wage inequality on social security provides support for the strategic effect implied by our model.

\subsection{Cross-Country Evidence}

In this subsection, we look at cross-country data as a further check. There are a number of empirical studies addressing the question of whether higher distributional skewness makes the constituency favor more redistributive legislation, following the work pioneered by Meltzer and Richard (1981). Our perspective is slightly different from that of the literature, with a focus on earnings inequality and the size of social security.

To deal with problems of data quality and comparability, we limit our cross-country analysis to a set of 19 OECD countries with reliable data on both earnings inequality and social security transfers. OECD national account statistics provides the ratio of the median earnings to the

\footnotetext{
${ }^{42}$ We describe in detail the empirical method and the results in a technical appendix, which is available from our webpage.

${ }^{43}$ Given the non-stationarity of our time-series data, such an impact leads to a permanent increase in wage inequality. The impulse response function in Figure 6 is based on specification (1) of Table 5 in the technical appendix. Other estimated VEC models deliver quantitatively similar results.
} 


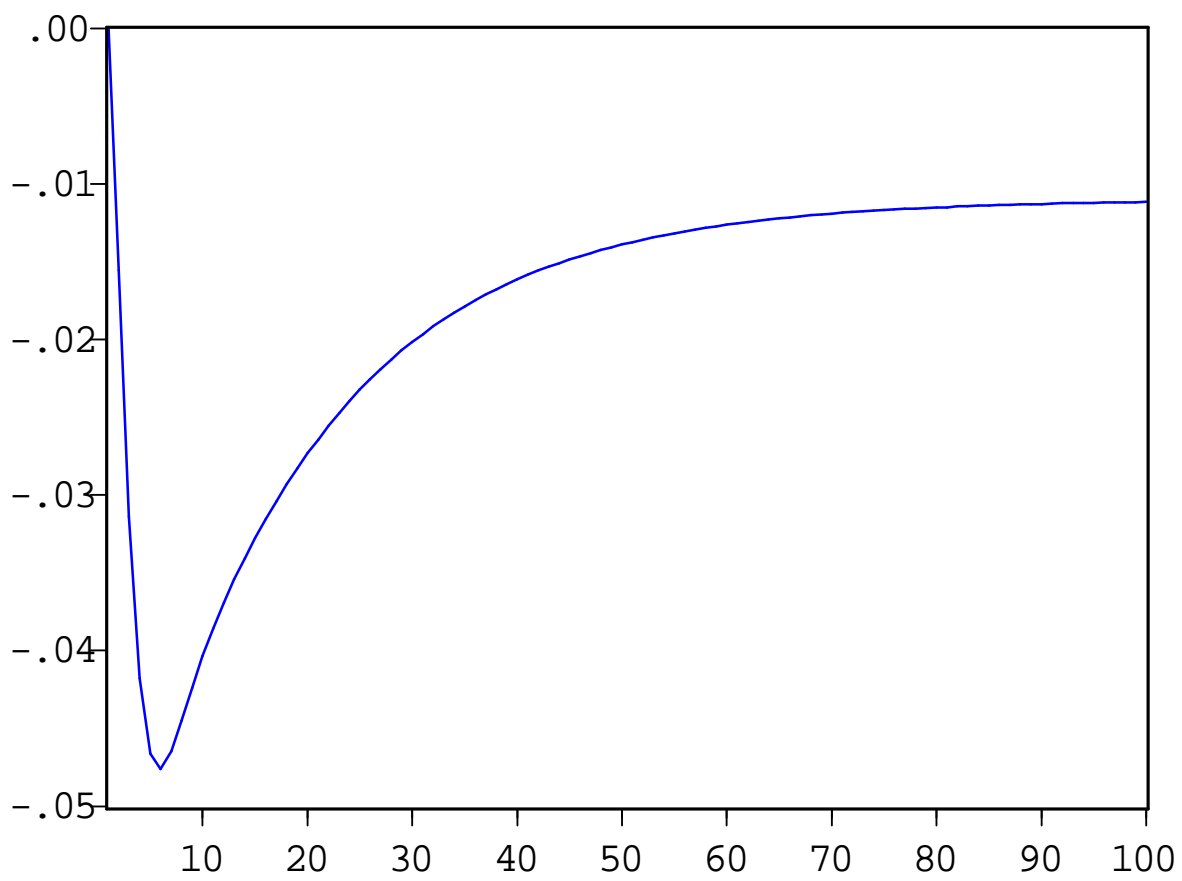

6.pdf

Figure 6: The Estimated Impulse Response Function of SSB

upper limit of earnings of employees in the 9th decile of the earnings distribution, denoted by $\mathrm{D} 5 / \mathrm{D} 1$, in a total of 21 countries. ${ }^{44}$ Social security transfers, measured as a percentage share of GDP (SST), are available from Economic Outlook of OECD. ${ }^{45}$ A combination of the two data sources gives a set of 19 OECD countries. ${ }^{46}$ We then compute the average earnings inequality and the average social security transfers for each country between 1980 and 2000, the period to which most of the observations belong. As shown by Figure 7, the social security expenditure in countries having smaller earnings inequality (measured by D5/D1) constitutes, on average, a larger percentage of GDP than in countries having larger earnings inequality, with a correlation coefficient of -0.36 .

In summary, both our time-series and cross-country evidence suggests negative correla-

\footnotetext{
${ }^{44}$ Earnings are measured on a gross basis, i.e., before deduction of income taxes and social security contribution paid by workers. They include basic wages and salaries, overtime payments, bonuses and gratuities, extra monthly payments, and regular and irregular allowances, but may exclude elements of the remuneration package of managers and other executives, such as stock options.

${ }^{45}$ The data for social security expenditure as a percentage of GDP until 1969 are from OECD Historical Statistics, various years. From 1970 onwards, the data are from OECD, National Accounts Statistics, Historical Statistics - Structure or composition of certain economic aggregates, Vol. 2002, release 01.

${ }^{46}$ The sample countries include Australia, Austria, Belgium, Canada, Denmark, Finland, France, Germany, Italy, Japan, Netherlands, New Zealand, Norway, Portugal, Spain, Sweden, Switzerland, United Kingdom and United States.
} 


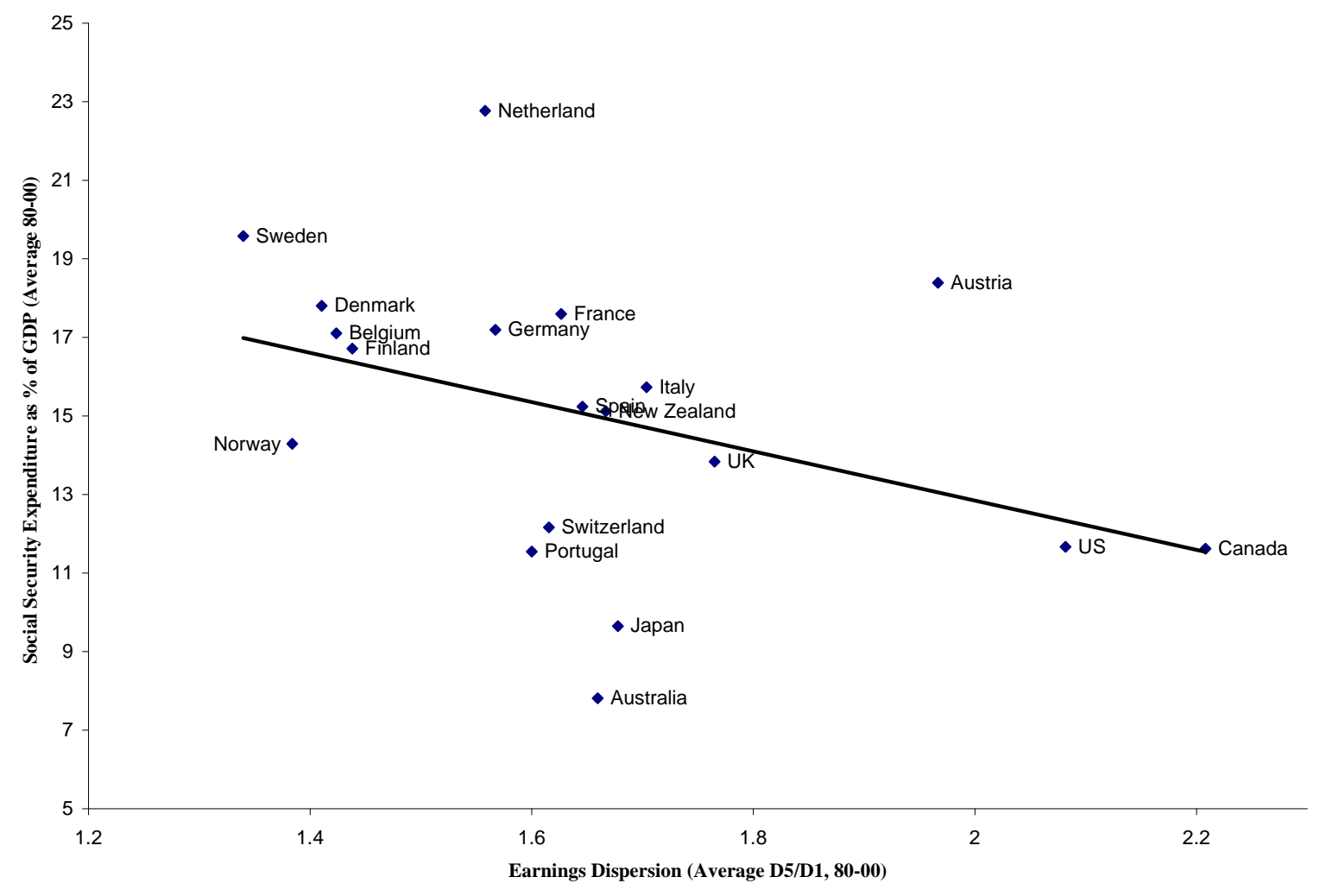

Figure 7: The Correlation between Earnings Inequality and The Size of Social Security Across OECD Countries

tions between wage inequality and the size of social security. The negative correlations pose a challenge to the standard politico-economic theory of redistribution. By contrast, our theory implies an inverted-U long-run correlation, which is in line with the cross-country observations. More importantly, our model delivers an unambiguous prediction regarding the shortrun dynamics of social security in response to permanent wage inequality shocks. The impulse response function estimated by VEC models provides strong empirical support for our theory.

\section{Conclusion}

This paper develops a dynamic politico-economic theory of social security to address two questions. First, how is social security sustained by a majority of (self-interested) working generations? Second, can political decisions be reconciled with the observed puzzling negative correlation between inequality and the size of social security, both across countries and across time periods? To this end, our model features the absence of altruism, commitment, reputation mechanism and electoral uncertainty. And we focus exclusively on Markov perfect equilibria 
with the median voter being taxpayers,

Our major finding is that the joint between Markovian tax policy and tax distortion on private investment shapes an intertemporal policy rule that links social security taxes positively over time. This intertemporal policy linkage not only serves as the key element in the political sustainability of social security, but also reveals a novel channel through which intragenerational inequality negatively affects inter-generational redistributive benefit and, thus, the size of social security. Thanks to the presence of this novel channel, our theoretical predictions are in line with the empirical observations. Our work, therefore, contrasts sharply with most previous studies, which imply opposite predictions by resorting to some ad-hoc intertemporal policy rule for sustaining social security in similar environments.

Furthermore, the mechanism described in this paper has the potential to explain other social programs that are characterized by temporal separation of contribution and benefit. One example is the government-sponsored health insurance program. An investigation into the sustainability and the evolution of such programs might be fruitful as they are growing fast and become an increasingly large portion of government expenditures. Another equally important policy issue is government debt. A key question is what prevents current generations from exploiting future unborn generations by issuing debt (see, e.g., Song, Storesletten and Zilibotti, 2007)? It will be interesting for future researchers to incorporate government borrowing into the current setup, to see how public debt interacts with social security. 


\section{References}

[1] Autor, David H., Lawrence F. Katz and Melissa Kearney (2005), "Trends in U.S. Wage Inequality: Re-Assessing the Revisionist”, NBER working paper, No. 11627

[2] Azariadis, Costas and Vincenzo Galasso (2002), "Fiscal Constitutions," Journal of Economic Theory, 103, 255-281.

[3] Benabou, Roland (1996), "Inequality and Growth," in Ben S. Bernanke and Julio J. Rotemberg, eds., NBER Macro Annual, Vol. 11, 11-74, MIT Press, Cambridge.

[4] Benabou, Roland (2000), "Unequal Societies: Income Distribution and the Social Contract," The American Economic Review, Vol. 90, 96-129.

[5] Boldrin, Michele and Aldo Rustichini (2000), "Political Equilibria with Social Security," Review of Economic Dynamics, 3, 41-78.

[6] Conde-Ruiz J. Ignacio and Paola Profeta (2007), "The Redistributive Design of Social Security System," Economic Journal, 117, 686-712.

[7] Conesa, Juan C. and Dirk Krueger (1999), "Social Security Reform with Heterogeneous Agents," Review of Economic Dynamics, 2, 757-795.

[8] Cooley, Thomas F. and Jorge Soares (1999), "A Positive Theory of Social Security Based on Reputation," Journal of Political Economy, 107, 135-160.

[9] Cremer, Helmuth, Philippe De Donder, Dario Maldonado and Pierre Pestieau (2007), "Voting over Type and Size of a Pension System When Some Individuals are Myopic," Journal of Public Economics, 91, 2041-2061

[10] Forni, Lorenzo (2005), "Social Security as Markov Equilibrium in OLG Models," Review of Economic Dynamics, 8, 178-194.

[11] Gonzalez-Eiras, Martin and Dirk Niepelt (2008), "The Future of Social Security," Journal of Monetary Economics, 55(2), 197-218.

[12] Hassler, John, Jose V. Rodriguez Mora, Kjetil Storesletten and Fabrizio Zilibotti (2003), "The Survival of the Welfare State," American Economic Review, 93, 87-112.

[13] Hassler, John, Kjetil Storesletten and Fabrizio Zilibotti (2007), "Democratic Public Good Provision," Journal of Economic Theory, 133, 127-151. 
[14] Judd, Kenneth L. (1992), "Projection Method for Solving Aggregate Growth Models," Journal of Economic Theory, 58, 410-452.

[15] Juhn, Chinhui, Kevin M. Murphy and Brooks Pierce (1993), "Wage Inequality and the Rise in Returns to Skill," Journal of Political Economy, 101, 410-442.

[16] Katz, Lawrence F. and Kevin M. Murphy (1992), "Changes in Relative Wages, 1963-87: Supply and demand Factors," Quarterly Journal of Economics, 107, 35-78.

[17] Klein, Paul, Per Krusell and Jose-Victor Rios-Rull (2008), "Time-Consistent Public Policy," Review of Economic Studies, 75, 789-808.

[18] Krusell, Per and Jose-Victor Rios-Rull (1999), "On the Size of US Government: Political Economy in the Neoclassical Growth Model," American Economic Review, 80, 1156-1181.

[19] Krusell, Per and Anthony A. Smith, Jr. (2003), "Consumption-Savings Decisions with Quasi-Geometric Discounting," Econometrica, 71, 365-375.

[20] Lindert, Peter H. (1996), "What Limits Social Spending," Explorations in Economic History, $33,1-34$.

[21] Martin, Patricia and David Weaver (2005), "Social Security, A Program and Policy History," Social Security Bulletin, Vol. 66, No.1

[22] Maskin, Eric and Jean Tirole (2003), "Markov Perfect Equilibrium, I. Observable Actions," Journal of Economic Theory, 100, 191-219.

[23] Meltzer, Allan and Scott Richard (1981), "A Rational Theory of the Size of Government," Journal of Political Economy, 89, 914-927.

[24] McCallum, Bennet (1983), "On Non-uniqueness in Rational Expectational Models," Journal of Monetary Economy, 11, 139-168.

[25] Moene, Karl O. and Michael Wallerstein (2001), "Inequality, Social Insurance, and Redistribution," American Political Science Review, Vol. 95, 859-974

[26] Mulligan, Casey B. and Xavier Sala-i-Martin (1999), "Gerontocracy, Retirement, and Social Security," NBER Working Paper, No. 7117.

[27] Perotti, Roberto (1996), "Growth, Income Distribution, and Democracy: What the Data Say," Journal of Economic Growth, 1, 149-87. 
[28] Persson, Torsten and Guido Tabellini (2000), Political Economics: Explaining Economic Policy, MIT Press, Cambridge, MA.

[29] Rodriguez, Francisco (1998), Essays on Redistribution, Development and the State, Ph.D. Dissertation, Harvard University.

[30] Song, Zheng (2005), "Essays on Dynamic Political Economy," PhD Dissertation, IIES, Stockholm University.

[31] Song, Zheng (2007), "Persistent Ideology and the Determination of Public Policies over Time," mimeo.

[32] Song, Zheng (2008), "The Dynamics of Inequality and Social Security in General Equilibrium," mimeo.

[33] Song, Zheng, Kjetil Storesletten and Fabrizio Zilibotti (2007), "Rotten Parents and Disciplined Children: A Dynamic Politico-Economic Theory of Public Expenditure and Debt," mimeo.

[34] Storesletten, Kjetil, Christopher I. Telmer and Amir Yaron (2004), "Consumption and Risk Sharing over the Life Cycle," Journal of Monetary Economics, 51, 609-633.

[35] Tabellini, Guido (2000), "A Positive Theory of Social Security," Scandinavian Journal of Economics, 102, 523-545.

[36] Wolfinger, Raymond E. and Steven J. Rosenstone (1980), Who votes?, Yale University Press, 1980. 


\section{Appendix}

\subsection{The Ramsey Allocation}

We assume that the planner's social welfare function is as follows:

$$
\begin{aligned}
& \max _{\left\{\tau_{t}\right\}_{t=0}^{\infty}} \sum_{t=0}^{\infty} \beta^{t} \sum_{j=u . s} \mu^{j} V_{t}^{u}\left(\tau_{t}, \tau_{t+1}, \tau_{t+2}, \tau_{t+3}\right) \\
& +\sum_{j=u . s} \mu^{j}\left(\left(1-\tau_{0}\right) w^{j} h_{-1}^{j}+\frac{y_{1}\left(\tau_{0}, \tau_{1}, \tau_{2}\right) \tau_{1}}{R}\right)+\tau_{0} p_{0},
\end{aligned}
$$

where $\mu^{u}=\lambda, \mu^{s}=1-\lambda$ and $p_{0} \equiv n\left(\lambda w^{u} h_{-1}^{u}+(1-\lambda) w^{s} h_{-1}^{s}\right)+n^{2}\left(\lambda w^{u} h_{0}^{u}\left(\tau_{0}, \tau_{1}\right)+(1-\lambda) w^{s} h_{0}^{s} h_{0}^{u}\left(\tau_{0}, \tau_{1}\right)\right)$. $\beta \in(0,1)$ is the discount factor of the planner on the welfare of all generations born after time 0 . That is, the utilitarian planner discounts each successive cohort with a factor $\beta . h_{-1}^{j}$ is the predetermined average human capital of the initial middle-aged. $V_{t}^{j}$ follows

$$
\begin{aligned}
V_{t}^{j}\left(\tau_{t}, \tau_{t+1}, \tau_{t+2}, \tau_{t+3}\right)= & \left(1-\tau_{t}\right) h_{t}^{j}\left(\tau_{t}, \tau_{t+1}\right)+\frac{\left(1-\tau_{t+1}\right) w^{j} h_{t}^{j}\left(\tau_{t}, \tau_{t+1}\right)}{R} \\
& +\frac{y_{t+2}\left(\tau_{t+1}, \tau_{t+2}, \tau_{t+3}\right) \tau_{t+2}}{R^{2}}-\frac{\left(h_{t}^{j}\left(\tau_{t}, \tau_{t+1}\right)\right)^{2}}{2} .
\end{aligned}
$$

We assume that $\tau_{t}$ cannot exceed one, but can be negative. A negative $\tau_{t}$ refers to the intergenerational redistribution from the old to working generations. For analytical convenience, we focus on interior solutions. (33) is a standard sequential problem. Note that the derivatives $\partial h_{t}^{j}\left(\tau_{t}, \tau_{t+1}\right) / \partial \tau_{t}=-w^{j}, \partial h_{t}^{j}\left(\tau_{t}, \tau_{t+1}\right) / \partial \tau_{t+1}=-w^{j} / R, \partial y_{t+1}\left(\tau_{t}, \tau_{t+1}, \tau_{t+2}\right) / \partial \tau_{t}=-n$, $\partial y_{t+1}\left(\tau_{t}, \tau_{t+1}, \tau_{t+2}\right) / \partial \tau_{t+1}=-n(n+1 / R)$ and $\partial y_{t+1}\left(\tau_{t}, \tau_{t+1}, \tau_{t+2}\right) / \partial \tau_{t+2}=-n^{2} / R$ are time-invariant.

For any $\tau_{t}$ with $t \geq 2$, the first-order condition is

$$
\begin{aligned}
& \left(\frac{-n \frac{n}{R} \tau_{t-1}}{R^{2}}\right)+\beta\left(\frac{-n\left(n+\frac{1}{R}\right) \tau_{t}+y_{t}\left(\tau_{t-1}, \tau_{t}, \tau_{t+1}\right)}{R^{2}}\right) \\
& +\beta^{2} \sum_{j=u, s} \mu^{j}\left(-\left(1-\tau_{t-1}\right)\left(w^{j}\right)^{2} / R-\frac{\left(1-\tau_{t}\right)\left(w^{j}\right)^{2} / R}{R}+\frac{-n \tau_{t+1}}{R^{2}}\right) \\
& +\beta^{3} \sum_{j=u, s} \mu^{j}\left(-\left(1-\tau_{t}\right)\left(w^{j}\right)^{2}-\frac{\left(1-\tau_{t+1}\right)\left(w^{j}\right)^{2}}{R}\right)=0 .
\end{aligned}
$$

(34) yields a second-order linear difference equation after some algebra

$$
\gamma_{1} \tau_{t+1}+\gamma_{2} \tau_{t}+\gamma_{3} \tau_{t-1}=\Delta
$$

where $\gamma_{1} \equiv \beta\left(\beta^{2}-\beta n / R-n^{2} / R^{2}\right) / R, \gamma_{2} \equiv \beta\left(\beta^{2}+\beta / R^{2}-2 n(n+1 / R) / R^{2}\right), \gamma_{3} \equiv \gamma_{1} / \beta$ and $\Delta \equiv \beta\left(\beta(1+1 / R)(\beta+1 / R)-n(1+n)(1+1 / R) / R^{2}\right)$. It immediately follows from 
(34) or (35) that the Ramsey allocation is independent of $w^{u}$ and $\lambda$. Intuitively, the linearity of consumption implies that the planner has no incentive for intra-generational redistribution. This explains why the social security tax is independent of wage inequality.

To understand further the determinants of long-run taxes in the Ramsey allocation, we consider two special cases of the discount factor: $\beta=n / R$ and $\beta=1 / R$. The first case implies that the planner weighs generations by their relative sizes and discounts their welfare by the interest rate. In the second, the planner discounts the utility of future generations more than the market rate. Assume the economy to be dynamic efficient so that $\beta<1$ holds.

Proposition 3 In the Ramsey allocation, we have

(1) If $\beta=1 / R$, the tax rate converges to a positive $\tau^{R} \in(0,1)$ in an oscillatory way, where

$$
\tau^{R}=\frac{\Delta}{\gamma_{1}+\gamma_{2}+\gamma_{3}}
$$

(2) If $\beta=n / R$, the tax rate converges to zero in an oscillatory way.

Proof. (1) The steady-state tax rate in the Ramsey allocation $\tau^{R}$ is solved by substituting $\tau^{R}$ for $\tau_{t}$ in (34). Substituting $\beta=1 / R$ into $\Delta$, it is immediate that $\Delta<0, \gamma_{1}<0, \gamma_{2}<0$ and $\gamma_{3}<0$ by $n>1$. Moreover, $|\Delta|<\left|\gamma_{1}+\gamma_{2}+\gamma_{3}\right|$. So $\tau^{R} \in(0,1)$. The eigenvalues of (35) are $\eta_{1}=\left(-\gamma_{2}+\sqrt{\gamma_{2}^{2}-4 \gamma_{1} \gamma_{3}}\right) /\left(2 \gamma_{1}\right)$ and $\eta_{2}=\left(-\gamma_{2}-\sqrt{\gamma_{2}^{2}-4 \gamma_{1} \gamma_{3}}\right) /\left(2 \gamma_{1}\right)$. Both of these have a negative real part. $n>1$ implies that $\gamma_{2}<\gamma_{1}+\gamma_{3}$. So $\eta_{1}$ and $\eta_{2}$ are real numbers, $\eta_{1} \in(0,1)$ and $\eta_{2}<-1$.

(2) Substituting $\beta=n / R$ into $\Delta$, it immediately follows that $\Delta=0$. The other proofs are the same as above.

We have discussed in the text the intuition of the result when $\beta=n / R$. The proposition implies that in the other case, where $\beta=1 / R$, the steady-state economy without social security is at the second best. Transferring resources from working generations to retirees improves welfare since the marginal rate of substitution between two consecutive generations now is smaller than the marginal rate of transformation. Consequently, the planner would like to impose a positive tax, purely for inter-generational redistribution. ${ }^{47}$

\footnotetext{
${ }^{47}$ More generally, if $\beta=(1+z(n-1)) / R$, then the above two cases refer to $z=0$ and $z=1$. For $z \in(0,1)$, numerical simulations show that the tax rate converges to a positive one.
} 


\subsection{The Definition of Parameters in Proposition 1}

Let $q \equiv\left(2-27 n^{2} R\left(w^{u}\right)^{2} / 2 n\right) / 27 n^{3} \cdot b_{0}, b_{1}, \pi_{0}, \pi_{1}$ are defined as follows

$$
\begin{aligned}
b_{1} & \equiv \sqrt[3]{-q+\sqrt{q^{2}-\frac{1}{729 n^{6}}}}+\sqrt[3]{-q-\sqrt{q^{2}-\frac{1}{729 n^{6}}}}-\frac{1}{3 n}, \\
\pi_{1} & \equiv-n\left(1+\left(n+\frac{1}{R}\right) b_{1}+\frac{n}{R} b_{1}^{2}\right), \\
b_{0} & \equiv \frac{\Pi b_{1}-\left(w^{u}\right)^{2}(1+R)}{n b_{1}\left(n+1 / R+n / R\left(1+b_{1}\right)\right)-\pi_{1}\left(1+2 b_{1}\right)-\left(w^{u}\right)^{2}}, \\
\pi_{0} & \equiv \Pi-n\left(\left(n+\frac{1}{R}\right) b_{0}+\frac{n}{R} b_{0}\left(1+b_{1}\right)\right),
\end{aligned}
$$

\subsection{Proof of Proposition 1}

To prove Proposition 1, we first suppose that the median voter is the middle poor and solve for the equilibrium policy rules. We then show that conditions for the middle poor to be the median voter are satisfied at each period.

Due to the linear-quadratic preference, it would be natural to guess that the policy rule $T$ is linear

$$
T\left(h_{-1}^{u}\right)=\phi_{0}+\phi_{1} h_{-1}^{u}
$$

where $\phi_{0}$ and $\phi_{1}$ are two undetermined coefficients. Substituting (41) into (11) solves

$$
H(\tau)=\left(1+\frac{1-\phi_{0}}{R}-\tau\right) \frac{w^{u}}{1+w^{u} \phi_{1} / R}
$$

Combining (41) and (42), we obtain a linear social contract $B$

$$
B(\tau)=b_{0}+b_{1} \tau
$$

where

$$
\begin{aligned}
b_{1} & \equiv-R w^{u} \phi_{1} /\left(R+w^{u} \phi_{1}\right) \\
b_{0} & \equiv \phi_{0}+w^{u} \phi_{1}\left(1+R-\phi_{0}\right) /\left(R+w^{u} \phi_{1}\right) \\
& =\phi_{0}\left(1+b_{1} / R\right)-b_{1}(1+1 / R)
\end{aligned}
$$

Equation (44) implies $b_{1}=-w^{u} \phi_{1}\left(1+b_{1} / R\right)$. Plugging into (45), we get

$$
\begin{aligned}
b_{0} & =\left(\phi_{0}+\phi_{1} w^{u}(1+1 / R)\right)\left(1+b_{1} / R\right) \\
& =\left(\phi_{0}+\phi_{1} \hat{h}^{u}\right)\left(1+b_{1} / R\right) \\
& =\hat{\tau}\left(1+\frac{b_{1}}{R}\right)
\end{aligned}
$$


where $\hat{h}^{u} \equiv w^{u}(1+1 / R)$ is the first-best human-capital investment, and $\hat{\tau} \equiv\left(\phi_{0}+\phi_{1} \hat{h}^{u}\right)$ is the baseline tax rate.

Plugging (43) into (16), the future tax base is

$$
Y(\tau)=\pi_{0}+\pi_{1} \tau
$$

where $\pi_{0}$ and $\pi_{1}$ are defined by (40) and (38), respectively. Then, the first-order condition (18) yields

$$
\begin{aligned}
\tau & =-\frac{b_{1} \pi_{0}+b_{0} \pi_{1}}{2 b_{1} \pi_{1}}+\frac{R w^{u}}{2 b_{1} \pi_{1}} h_{-1}^{u} \\
& =\widehat{\phi}_{0}+\widehat{\phi}_{1} h_{-1}^{u}
\end{aligned}
$$

Our definition of Markov Perfect Equilibrium pins down $\phi_{0}$ and $\phi_{1}$ in (41) as a fixed point

$$
\begin{aligned}
\phi_{0} & =\widehat{\phi}_{0}=-\frac{b_{1} \pi_{0}+b_{0} \pi_{1}}{2 b_{1} \pi_{1}}, \\
\phi_{1} & =\widehat{\phi}_{1}=\frac{R w^{u}}{2 b_{1} \pi_{1}} .
\end{aligned}
$$

Equation (50) implies a four-order polynomial of $b_{1}$ :

$$
2 n \frac{n}{R} b_{1}^{4}+2 n\left(n+\frac{1}{R}\right) b_{1}^{3}+2 n b_{1}^{2}-\left(w^{u}\right)^{2} b_{1}-R\left(w^{u}\right)^{2}=0 .
$$

Factorizing (51), one root of $b_{1}$ equals $-R$, which should be omitted by the necessary condition $b_{1}>0$ for the sustainability of social security. The other three roots solve

$$
n b_{1}^{3}+b_{1}^{2}-\Psi=0
$$

where $\Psi \equiv R\left(w^{u}\right)^{2} / 2 n$. Rearrange (52):

$$
b_{1}^{2}=\frac{\Psi}{1+n b_{1}} .
$$

It is straightforward to see that the LHS and the RHS of (53) have a unique cross with $b_{1}>0$, which gives the only real root of $b_{1}$, i.e., (37). The other undetermined coefficient $b_{0}$ can easily be solved.

Then we need to check whether $T\left(h_{-1}^{u}\right) \in[\underline{\tau}, \bar{\tau}]$ for all $h_{-1}^{u} \in[\underline{h}, \bar{h}]$. This gives the existence conditions (20) and (21). Finally, we need to check whether the middle poor can be the median voter or, equivalently, the validity of $\tau^{m, u} \leq \tau^{o}$ in (15). Note that the LHS of (22) is the highest tax rate for which the middle poor would vote. Given the equilibrium social contract $B$, the current tax base $y_{t}$ can be written as

$$
y=Y_{c}\left(h_{-1}^{u}, \tau\right)=n\left(\frac{h_{-1}^{u}}{w^{u}}+n\left(1-\tau+\frac{1-B(\tau)}{R}\right)\right) .
$$


Maximizing the indirect utility of the old, (14) solves $\tau^{o}=\min \left\{\bar{\tau},-Y_{c}\left(h_{-1}^{u}, \tau\right) /\left(\partial Y_{c}\left(h_{-1}^{u}, \tau\right) / \partial \tau\right)\right\}$. In words, the old choose $\tau^{o}$ to attain the top of the Laffer curve. Substituting the linear tax policy rule $B$ into (54), we have

$$
\tau^{o}=\min \left\{\bar{\tau}, \frac{1+1 / R-b_{0} / R+h_{-1}^{u} / n w^{u}}{2\left(1+b_{1} / R\right)}\right\},
$$

where $b_{0}$ and $b_{1}$ are defined in (39) and (37), respectively. Since $\tau^{o}$ increases in $h_{-1}^{u}$, the minimum $\tau^{o}$ locates at $h_{-1}^{u}=\underline{h}$, which gives the RHS of (22). Therefore, (22) says that the lowest tax rate for which the old would vote is larger than the highest tax for which the middle poor would vote.

\subsection{Proof of Lemma 1}

Differentiating (52) with respect to $w^{u}$, we have

$$
\frac{\partial b_{1}}{\partial w^{u}}=\frac{\partial \Psi / \partial w^{u}}{3 n b_{1}^{2}+2 b_{1}}
$$

Since $b_{1}>0, \operatorname{sgn}\left(\partial b_{1} / \partial w^{u}\right)=\operatorname{sgn}\left(\partial \Psi / \partial w^{u}\right)$. It immediately follows that $\partial \Psi / \partial w^{u}>0$.

\subsection{Proof of Corollary 1}

Note that $T(\bar{h}) \geq \underline{\tau}=0$ requires $\phi_{0}+\phi_{1} \bar{h} \geq 0$, which implies $\phi_{0} \leq-\phi_{1} w^{u}(1+R) / R$. By the definition of $b_{0}$ in (46), it is easily shown that $b_{0} \geq 0$. On the other hand, $T(0) \leq \bar{\tau}$ implies that $b_{0}+b_{1} \bar{\tau} \leq \bar{\tau}$. Together with $b_{1}>0$, we have $b_{1} \leq \bar{\tau}$ and $b_{0} /\left(1-b_{1}\right) \in[0, \bar{\tau}]$.

\subsection{Proof of Proposition 2}

We first prove that $\phi_{0}$ is increasing in $w^{u}$. From (49), we can write

$$
\phi_{0}=\frac{b_{1} n(1+n)(1+1 / R)-\left(\begin{array}{c}
b_{1} n\left(n+\frac{1}{R}+\frac{n}{R}\left(1+b_{1}\right)\right) \\
+n\left(1+n b_{1}\right)\left(1+b_{1} / R\right)
\end{array}\right) b_{0}}{2 b_{1} n\left(1+n b_{1}\right)\left(1+b_{1} / R\right)} .
$$

Using the fact that $b_{0}=\phi_{0}\left(1+b_{1} / R\right)-b_{1}(1+1 / R),(56)$ becomes

$$
\phi_{0}=\frac{-\left(\begin{array}{c}
b_{1} n(1+n)(1+1 / R) \\
+n\left(1+n b_{1}\right)\left(1+b_{1} / R\right)
\end{array}\right)\left(\phi_{0}\left(1+b_{1} / R\right)-b_{1}(1+1 / R)\right)}{2 b_{1} n\left(1+n b_{1}\right)\left(1+b_{1} / R\right)} .
$$

Equation (57) delivers an implicit function for $\phi_{0}$, with

$$
\phi_{0}=f\left(\phi_{0}, b_{1}\right),
$$


where $f$ is defined as the RHS of (57). By Lemma 1, we only need to prove

$$
\frac{d \phi_{0}}{d b_{1}}=\frac{f_{b_{1}}}{1-f_{\phi_{0}}}>0
$$

where $f_{x}$ denotes the partial derivative of $f$ to $x$. It is easy to show that

$$
f_{\phi_{0}}=-\frac{1}{2}\left[\frac{n+1 / R+\frac{n}{R}\left(1+b_{1}\right)}{1+n b_{1}}+\frac{1+b_{1} / R}{b_{1}}\right]<0 .
$$

Therefore, $\frac{d \phi_{0}}{d b_{1}}>0$ iff $f_{b_{1}}>0$. Taking derivatives, we find that

$$
f_{b_{1}}=\frac{\left(n^{2}(2+1 / R)\right) b_{1}^{2}+2 n b_{1}+1}{\left(1+n b_{1}\right)^{2} b_{1}^{2}} \frac{\phi_{0}}{2}-\frac{1+1 / R}{2} \frac{n^{2}}{\left(1+n b_{1}\right)^{2}} .
$$

So, it is equivalent to prove

$$
\phi_{0}>\frac{(1+1 / R) n^{2} b_{1}^{2}}{n^{2}(2+1 / R) b_{1}^{2}+2 n b_{1}+1} .
$$

Using (56), (59) can be rewritten as

$$
\frac{1+n+Q}{\left(1+b_{1} / R\right)\left(2 b_{1}\left(1+n b_{1}\right)+Q\right)}>\frac{n^{2} b_{1}}{n^{2}(2+1 / R) b_{1}^{2}+2 n b_{1}+1} .
$$

where

$$
Q \equiv 2\left(1+(n+1 / R) b_{1}+n b_{1}^{2} / R\right)+n b_{1} / R-1 .
$$

Rearranging the inequality, we need to prove that

$$
(1+n)\left(n^{2}(2+1 / R) b_{1}^{2}+2 n b_{1}+1\right)+\left(2 n^{2} b_{1}^{2}+2 n b_{1}+1\right) Q>n^{2} b_{1}\left(1+b_{1} / R\right) 2 b_{1}\left(1+n b_{1}\right)+n^{2} b_{1} Q
$$

Note that the RHS of the inequality (60) is equal to

$$
\begin{aligned}
& \left(2 n^{2} b_{1}^{2}+2 n^{2} b_{1}^{3} / R\right)\left(1+n b_{1}\right)+n^{2} b_{1}\left(1+(2 n+2 / R+n / R) b_{1}+2 n b_{1}^{2} / R\right) \\
= & 2 n^{2} b_{1}^{2}+2 n^{2} b_{1}^{3} / R+2 n^{3} b_{1}^{3}+2 n^{3} b_{1}^{4} / R+n^{2} b_{1}+n^{2}(2 n+2 / R+n / R) b_{1}^{2}+2 n^{3} b_{1}^{4} / R \\
= & 4 n^{3} b_{1}^{4} / R+\left(2 n^{2} / R+2 n^{3}\right) b_{1}^{3}+n^{2}(2+2 n+2 / R+n / R) b_{1}^{2}+n^{2} b_{1} .
\end{aligned}
$$

The LHS of the inequality (60) is equal to

$$
\begin{aligned}
& 4 n^{3} b_{1}^{4} / R+2 n^{2}(2 n+2 / R+n / R) b_{1}^{3} \\
& +\left(\begin{array}{c}
2 n^{2}+2 n^{3}+n^{2} / R+n^{3} / R+2 n^{2} \\
+2 n(2 n+2 / R+n / R)+2 n / R+4 n^{2} / R+2 n / R
\end{array}\right) b_{1}^{2} \\
& +\left(2 n+2 n^{2}+2 n+2 n+2 / R+n / R\right) b_{1}+2+n
\end{aligned}
$$

It is then immediate that the LHS is greater than the RHS of (60) in (61). 
We next prove that $\phi_{1}$ is also increasing in $w^{u}$. (50) gives

$$
\phi_{1}=\frac{1}{2 n} \frac{R / \phi_{1}+w^{u}}{1+\left(n+\frac{1}{R}\right) b_{1}+\frac{n}{R} b_{1}^{2}} .
$$

As for (57), (62) delivers an implicit function for $\phi_{1}$, with

$$
\phi_{1}=g\left(\phi_{1}, w^{u}\right)
$$

where $g$ is defined as the RHS of (62). Following the same procedure as above, it is straightforward that $\frac{d \phi_{1}}{d w^{u}}>0$ iff $g_{w^{u}}>0$. Taking derivatives, we find that

$$
g_{w^{u}}=\frac{1}{2 n}\left[\frac{1}{1+\left(n+\frac{1}{R}\right) b_{1}+\frac{n}{R} b_{1}^{2}}+\left(R / \phi_{1}+w^{u}\right) \frac{\partial \frac{1}{1+\left(n+\frac{1}{R}\right) b_{1}+\frac{n}{R} b_{1}^{2}}}{\partial w^{u}}\right]
$$

It is easy to see that $\partial\left(\frac{1}{1+\left(n+\frac{1}{R}\right) b_{1}+\frac{n}{R} b_{1}^{2}}\right) / \partial w^{u}<0$, as $\partial b_{1} / \partial w^{u}>0$. Also, notice that (62) implies that $R / \phi_{1}+w^{u}<0$ as $\phi_{1}<0$. Therefore, the second argument in the bracket is positive. This, together with the positive sign of the first argument, establishes that $g_{w^{u}}>0$. 